\title{
Bulk and Surface Chemistry of the Niobium MAX and MXene Phases from Multinuclear Solid-State NMR Spectroscopy
}

Kent J. Griffith, ${ }^{1,2, \dagger}$ Michael A. Hope, ${ }^{1, \dagger}$ Philip J. Reeves, ${ }^{1}$ Mark Anayee, ${ }^{3}$ Yury Gogotsi, ${ }^{3}$

Clare P. Grey ${ }^{1}$

${ }^{1}$ Department of Chemistry, University of Cambridge, Cambridge, CB2 1EW, United Kingdom

${ }^{2}$ Department of Chemistry and Department of Materials Science and Engineering, Northwestern University, Evanston, IL 60208, United States

${ }^{3}$ A. J. Drexel Nanomaterials Institute, and Department of Materials Science and Engineering, Drexel University, Philadelphia, PA 19104, United States

†Authors contributed equally

\section{Abstract}

MXenes, derived from layered MAX phases, are a class of two-dimensional materials with emerging applications in energy storage, electronics, catalysis, and other fields due to their high surface areas, metallic conductivity, biocompatibility and attractive optoelectronic properties. MXene properties are heavily influenced by their surface chemistry, but a detailed understanding of the surface functionalization is still lacking. Solid-state nuclear magnetic resonance (NMR) spectroscopy is sensitive to the interfacial chemistry, the phase purity including the presence of amorphous/nanocrystalline phases, and the electronic properties of the MXene and MAX phases. In this work, we systematically study the chemistry of Nb MAX and MXene phases, $\mathrm{Nb}_{2} \mathrm{CT}_{x}$ and $\mathrm{Nb}_{4} \mathrm{C}_{3} \mathrm{~T}_{x}$, with their unique electronic and mechanical properties, using solid-state NMR spectroscopy and examine a variety of nuclei $\left({ }^{1} \mathrm{H},{ }^{13} \mathrm{C},{ }^{19} \mathrm{~F}\right.$, ${ }^{27} \mathrm{Al}$ and ${ }^{93} \mathrm{Nb}$ ) with a range of one- and two-dimensional correlation, wideline, high-sensitivity, high-resolution, and/or relaxation-filtered experiments. Hydroxide and fluoride terminations are identified, found to be intimately mixed, and their chemical shifts are compared with other MXenes. This multinuclear NMR study demonstrates that diffraction alone is insufficient to characterize the phase composition of MAX and MXene samples as numerous amorphous or 
nanocrystalline phases are identified including $\mathrm{NbC}, \mathrm{AlO}_{6}$ species, aluminum nitride or oxycarbide, $\mathrm{AlF}_{3} \cdot n \mathrm{H}_{2} \mathrm{O}, \mathrm{Nb}$ metal, and unreacted $\mathrm{MAX}$ phase. To the best of our knowledge, this is the first study to examine the transition-metal resonances directly in MXene samples, and the first ${ }^{93} \mathrm{Nb}$ NMR of any MAX phase. The insights from this work are employed to enable the previously-elusive assignment of the complex overlapping ${ }^{47 / 49} \mathrm{Ti}$ NMR spectrum of $\mathrm{Ti}_{3} \mathrm{AlC}_{2}$. The results and methodology presented here provide fundamental insights on MAX and MXene phases and can be used to obtain a more complete picture of MAX and MXene chemistry, to prepare realistic structure models for computational screening, and to guide the analysis of property measurements. 


\section{Introduction}

a)
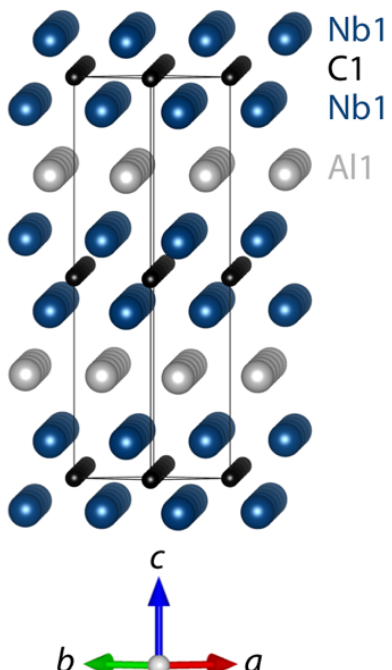

c)
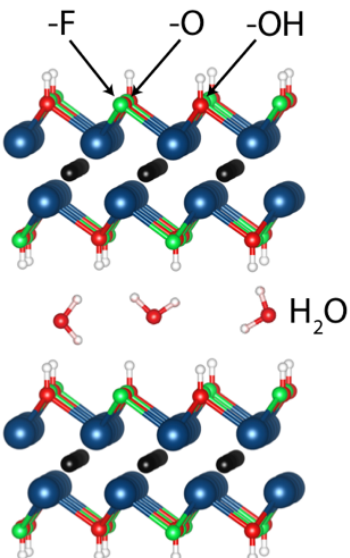
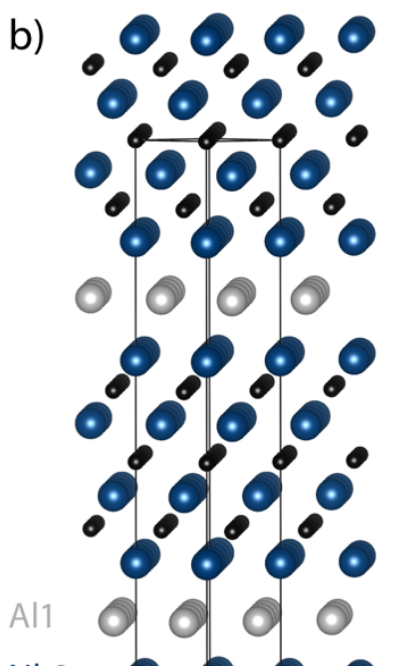
- 10. $\% \%$
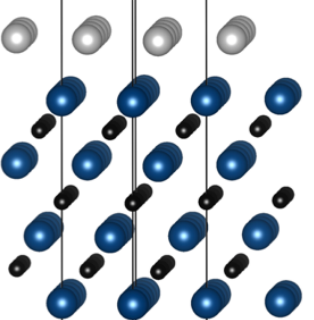

$\mathrm{Nb} 2$

$\mathrm{Nb2}$

$\mathrm{Nb} 1$

C1

$\mathrm{Nb} 1$

$\mathrm{C} 2$ $\mathrm{Nb} 2$

d)

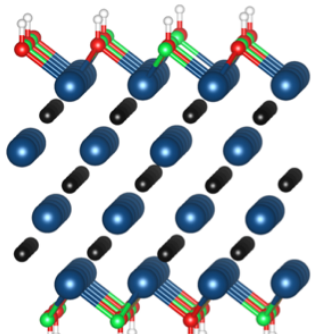

MAX phases $(M=$ early transition metal; $A$ $=\mathrm{Al}, \mathrm{Si}, \mathrm{Ga} ; \mathrm{X}=\mathrm{C}, \mathrm{N})$ are a large class of 3D layered ternary compounds with the stoichiometry $\mathrm{M}_{n+1} \mathrm{AX}_{n}(1 \leq n \leq 3) \cdot{ }^{1-4}$ MXenes are a similarly diverse class of 2D compounds derived from MAX phases via etching of the A-site atoms. ${ }^{5}$ It is wellestablished that MXenes are surfaceterminated, and thus better represented by the formula $\mathrm{M}_{n+1} \mathrm{X}_{n} \mathrm{~T}_{x}(\mathrm{~T}=$ termination), however the nature of the surface composition, coordination, and spatial arrangements are exceptionally challenging to ascertain (Figure 1). Both material

Figure 1 - Crystal structures of the niobium MAX and surface-terminated MXene compounds. In a) $\mathrm{Nb}_{2} \mathrm{AlC}$ and b) $\mathrm{Nb}_{4} \mathrm{AlC}_{3}$, the crystallographic sites are labeled and the unit cells are outlined. Table 1 describes the local coordination around each atom. The corresponding MXenes c) $\mathrm{Nb}_{2} \mathrm{CT}_{x}$ and $\mathrm{d}$ ) $\mathrm{Nb}_{4} \mathrm{C}_{3} \mathrm{~T}_{x}$, showing $-\mathrm{F},-\mathrm{O}$ and $-\mathrm{OH}$ terminations; two layers and interlayer water are shown for $\mathrm{Nb}_{2} \mathrm{CT}_{x}$.

families have extremely diverse applications: MAX phases are used for industrial components such as heating elements and gas burner nozzles with high temperature applications ${ }^{1,3,6}$ and MXenes are being tested as functional materials for applications in energy storage, ${ }^{7,8}$ hydrogen $^{9,10}$ and oxygen ${ }^{11,12}$ evolution catalysis, cancer therapeutics, ${ }^{13}$ electromagnetic interference shielding, ${ }^{14,15}$ and wireless communication ${ }^{16}$. The electronic and functional properties of MXenes depend strongly on the surface terminations, ${ }^{17-}$ ${ }^{20}$ so a deeper understanding of the surface chemistry is required to optimize the performance in these applications. 
As the first reported MXene, $\mathrm{Ti}_{3} \mathrm{C}_{2} \mathrm{~T}_{x}$ has been the most thoroughly studied member of this family, while many other MXenes have been, and continue to be, synthesized and applied to diverse functions. In this work, on the other hand, we focus on the less studied $4 d$ transition metal-based niobium MAX and MXene phases including $\mathrm{Nb}_{4} \mathrm{AlC}_{3}, \mathrm{Nb}_{4} \mathrm{C}_{3} \mathrm{~T}_{x}, \mathrm{Nb}_{2} \mathrm{AlC}$, and $\mathrm{Nb}_{2} \mathrm{CT}_{x}$, and $\mathrm{Nb}_{2} \mathrm{SnC}$. While $\mathrm{Nb}_{2} \mathrm{AlC}^{21}$ and $\mathrm{Nb}_{2} \mathrm{SnC}^{22}$ were reported in the $1960 \mathrm{~s}$, it was not until the 2000s that $\mathrm{Nb}_{4} \mathrm{AlC}_{3}$ emerged ${ }^{23}$ via a synthesis strategy borrowed from the synthesis of the Ta MAX series. The syntheses of $\mathrm{Nb}_{2} \mathrm{CT}_{x}{ }^{24}$ and $\mathrm{Nb}_{4} \mathrm{C}_{3} \mathrm{~T}_{x}{ }^{25}$ MXenes were then reported in 2013 and 2014, respectively, by selective etching of $\mathrm{Al}$ from $\mathrm{Nb}_{2} \mathrm{AlC}$ and $\mathrm{Nb}_{4} \mathrm{AlC}_{3}$, following the same methodology as for $\mathrm{Ti}_{3} \mathrm{C}_{2} \mathrm{~T}_{x}$. Neither the intermediate compound $\mathrm{Nb}_{3} \mathrm{AlC}_{2}$ nor its MXene derivative have been reported; density functional theory (DFT) calculations suggest that this 312 MAX phase is dynamically unstable. ${ }^{26}$ The Nb MAX and MXene phases have various interesting properties and potential applications: $\mathrm{Nb}_{2} \mathrm{CT}_{x}{ }^{24,27}$ and $\mathrm{Nb}_{4} \mathrm{C}_{3} \mathrm{~T}_{x}^{28,29}$ have attracted recent interest as lithium-ion battery anodes, $\mathrm{Nb}_{4} \mathrm{C}_{3} \mathrm{~T}_{x}$ is one of the most conductive and strongest MXene phases, ${ }^{25}$ which makes it promising for field-effect transistors and mechanical applications, ${ }^{30}$ and $\mathrm{Nb}_{2} \mathrm{SnC}^{31}$ and $\mathrm{Nb}_{2} \mathrm{AlC}^{32}$ are superconducting up to $7.8 \mathrm{~K}$ and $0.440 \mathrm{~K}$, respectively. Superconductivity was recently observed in $\mathrm{Nb}_{2} \mathrm{CT}_{x}$ at 4.5 to $7.1 \mathrm{~K}$, the temperature depending on the surface termination. ${ }^{33}$

The structures of the Nb MAX and MXene phases are shown in Figure 1, with the firstshell coordination numbers and geometry given in Table $1 . \mathrm{Nb}_{4} \mathrm{AlC}_{3}$ and $\mathrm{Nb}_{4} \mathrm{C}_{3} \mathrm{~T}_{x}$ contain two distinct crystallographic $\mathrm{Nb}$ sites and two $\mathrm{C}$ sites. $\mathrm{Nb} 2$ and $\mathrm{C} 2$ are the sites nearer to the $\mathrm{Al} /$ etched layer and will thus be referred to as 'external' while $\mathrm{Nb} 1$ and $\mathrm{C} 1$ are denoted 'internal' following the assignments in ICSD crystal structure files $160755^{23}$ and $606236^{21}$. $\mathrm{Nb}_{2} \mathrm{AlC}$ and $\mathrm{Nb}_{2} \mathrm{CT}_{x}$ contain one $\mathrm{Nb}$ site and one $\mathrm{C}$ site; these are necessarily 'external'. Both MAX phases contain a single Al environment with trigonal prismatic coordination to six 
niobium atoms. Note that the MXene coordination in Table 1 is described in the absence of termination groups $(\mathrm{T})$.

Table 1 - Local atomic sites in Nb MAX and MXene phases.

\begin{tabular}{|c|c|c|c|c|c|}
\hline \multirow[b]{2}{*}{ Compound } & \multicolumn{5}{|c|}{ Coordination by Crystallographic Site } \\
\hline & $\mathrm{Nb} 1$ & $\mathrm{Nb} 2$ & $\mathrm{Al}$ & C1 & $\mathrm{C} 2$ \\
\hline $\mathrm{Nb}_{2} \mathrm{AlC}$ & $\mathrm{fac}-\mathrm{NbAl}_{3} \mathrm{C}_{3}(\mathrm{D})$ & - & $\mathrm{AlNb}_{6}(\mathrm{P})$ & $\mathrm{CNb}_{6}(\mathrm{R})$ & - \\
\hline $\mathrm{Nb}_{4} \mathrm{AlC}_{3}$ & $\mathrm{NbC}_{6}(\mathrm{R})$ & fac- $\mathrm{NbAl}_{3} \mathrm{C}_{3}(\mathrm{D})$ & $\mathrm{AlNb}_{6}(\mathrm{P})$ & $\mathrm{CNb}_{6}(\mathrm{R})$ & $\mathrm{CNb}_{6}(\mathrm{R})$ \\
\hline $\mathrm{Nb}_{2} \mathrm{C}$ & $\mathrm{NbC}_{3}(\mathrm{~T})$ & - & - & $\mathrm{CNb}_{6}(\mathrm{R})$ & - \\
\hline $\mathrm{Nb}_{4} \mathrm{C}_{3}$ & $\mathrm{NbC}_{3}(\mathrm{~T})$ & $\mathrm{NbC}_{3}(\mathrm{~T})$ & - & $\mathrm{CNb}_{6}(\mathrm{R})$ & $\mathrm{CNb}_{6}(\mathrm{R})$ \\
\hline
\end{tabular}

$\mathrm{D}=$ distorted octahedron; $\mathrm{R}=$ regular octahedron; $\mathrm{T}=$ trigonal pyramid; $\mathrm{P}=$ prismatic.

Solid-state NMR spectroscopy is a versatile toolkit that is sensitive to bonding and electronic properties with the ability to probe different elements individually. Additionally, there is no requirement for long-range periodic order in NMR, therefore, it can be readily applied to defect and surface chemistry as well as to nanoparticles. In particular, NMR can reveal the presence of amorphous impurities which are invisible to diffraction techniques. All the elements in the niobium aluminum carbide phases are NMR active and relatively accessible: ${ }^{13} \mathrm{C}$ is $\mathrm{I}=1 / 2$ with a natural abundance of $1.1 \%$, while ${ }^{93} \mathrm{Nb}(\mathrm{I}=9 / 2)$ and ${ }^{27} \mathrm{Al}(\mathrm{I}=5 / 2)$ are $100 \%$ naturally abundant quadrupolar nuclei. The quadrupolar nature of the latter two nuclei means that they are extremely sensitive to the symmetry of their local environment. Despite the analytical utility, NMR investigations of MAX and MXene phases are sparse. Lue et al. measured static ${ }^{27} \mathrm{Al}$ NMR spectra of the $3 d$ transition metal MAX series $\mathrm{Ti}_{2} \mathrm{AlC}, \mathrm{V}_{2} \mathrm{AlC}$, and $\mathrm{Cr}_{2} \mathrm{AlC}$, ${ }^{34}$ finding relatively long nuclear relaxation times and systematically decreasing nuclear quadrupole coupling constants and Knight shifts from Ti toward $\mathrm{Cr}^{34}$ The first NMR study of a MXene was by Harris et al. who identified $-\mathrm{OH}$ and $-\mathrm{F}$ surface terminations in $\mathrm{V}_{2} \mathrm{C}$ by ${ }^{1} \mathrm{H}$ and ${ }^{19} \mathrm{~F}$ NMR spectroscopy and demonstrated the proximity of ${ }^{1} \mathrm{H}$ nuclei to the MXene surfaces by using ${ }^{1} \mathrm{H} \rightarrow{ }^{13} \mathrm{C}$ cross polarization $(\mathrm{CP}) .{ }^{35}$ Hope et al. later quantified the concentrations of $-\mathrm{OH}$ and $-\mathrm{F}$ terminations on $\mathrm{Ti}_{3} \mathrm{C}_{2}$ MXene, which were found to be highly dependent on the synthesis method, and showed the terminations to be intimately mixed using ${ }^{1} \mathrm{H}-{ }^{19} \mathrm{~F}$ NMR 
correlation experiments. ${ }^{36}$ These observations have been extended to further $\mathrm{Ti}_{3} \mathrm{C}_{2} \mathrm{~T}_{x}$ syntheses and preparation conditions in a pair of very recent reports. ${ }^{37,38}$

In this work, a comprehensive multinuclear NMR study $\left({ }^{93} \mathrm{Nb},{ }^{27} \mathrm{Al},{ }^{13} \mathrm{C},{ }^{1} \mathrm{H}\right.$, and $\left.{ }^{19} \mathrm{~F}\right)$ of the bulk structures and surface chemistry of the known $\mathrm{Nb}_{n+1} \mathrm{AlC}_{n} \mathrm{MAX}$ and $\mathrm{Nb}_{n+1} \mathrm{C}_{n} \mathrm{~T}_{x}$ MXene phases is performed with a range of one- and two-dimensional techniques, ${ }^{39}$ with additional comparisons to $\mathrm{Nb}_{2} \mathrm{SnC}$ and the ${ }^{47 / 49} \mathrm{Ti} \mathrm{NMR}$ of $\mathrm{Ti}_{3} \mathrm{AlC}_{2}$ MAX phase. These experiments are supported by DFT-based electronic structure calculations of the electric field gradient (EFG) at the nucleus. The quadrupolar parameters determined by high-resolution magic-angle spinning (MAS) and static wideline ${ }^{93} \mathrm{Nb}$ and ${ }^{27} \mathrm{Al}$ spectra give insights on the local structures of the MAX phases, while ${ }^{93} \mathrm{Nb}$ and ${ }^{13} \mathrm{C}$ spectra reveal the nature of the etching to the corresponding MXene phases, with the ${ }^{93} \mathrm{Nb}$ NMR further confirming that the latter are surface terminated. ${ }^{1} \mathrm{H},{ }^{19} \mathrm{~F}$ and ${ }^{93} \mathrm{Nb}$ two-dimensional NMR spectroscopy then identifies the chemistry and connectivity of the MXene surface terminations. Finally, the presence of diffraction-silent side-products is confirmed, including the observation of aluminum oxides via the ${ }^{27} \mathrm{Al}$ NMR spectra. Overall, these results have important implications for the synthesis, characterization, and functional properties of $\mathrm{Nb}$ MAX and MXene phases.

\section{Experimental}

Synthesis. $\mathrm{Nb}_{2} \mathrm{AlC}$ MAX phase was prepared as described per Naguib et al. ${ }^{24}$ Elemental powders of niobium ( $99.9 \%$ metals basis, 325 mesh), aluminum (99.8\% purity, 300 mesh), and carbon black (99\% purity, 300 mesh) were mixed in a plastic jar with a ratio of 2:1.1:1 Nb:Al:C and ball milled. The powder was placed into an alumina boat and heated under Ar flow to 1600 ${ }^{\circ} \mathrm{C}$, with a ramp rate of $4{ }^{\circ} \mathrm{C} \cdot \mathrm{min}^{-1}$, and sintered for $4 \mathrm{~h}$. After natural cooling to room temperature, the MAX phase was milled into powder and sieved through a 400-mesh sieve. 
To prepare $\mathrm{Nb}_{2} \mathrm{CT}_{x}$ MXene, $1.0 \mathrm{~g}$ of $\mathrm{Nb}_{2} \mathrm{AlC}$ powder was transferred into $20 \mathrm{~mL}$ of $\mathrm{HF}$ (aqueous, 49\%, Millipore-Sigma) over $60 \mathrm{~s}$ and stirred for $48 \mathrm{~h}$ at $50{ }^{\circ} \mathrm{C}$. The mixture was washed several times by centrifugation at $3500 \mathrm{rpm}(5 \mathrm{~min} /$ cycle $)$, the supernatant was decanted, and deionized (DI) water was added until the supernatant reached a $\mathrm{pH}>6$. Multilayered MXene powder was collected by filtration through a cellulose acetate membrane $\left(0.45 \mu \mathrm{m}\right.$ pore size). The delamination of $\mathrm{Nb}_{2} \mathrm{CT}_{x}$ was carried out by transferring $1.0 \mathrm{~g}$ of MXene powder into $10 \mathrm{~mL}$ of a diluted tetramethylammonium hydroxide (TMAOH) solution (25\% in $\mathrm{H}_{2} \mathrm{O}$, Millipore-Sigma). The solution was stirred overnight $(\sim 18 \mathrm{~h})$ at room temperature. To remove excess TMAOH, the mixture was washed by centrifugation with DI water $(50 \mathrm{~mL})$ at $3500 \mathrm{rpm}$ for $20 \mathrm{~min}$ followed by decantation of the supernatant. The process was repeated until the supernatant reached a $\mathrm{pH}<8$. Then, the sediment was dispersed in 50 $\mathrm{mL}$ of deionized water and sonicated for $1 \mathrm{~h}$ in an ice-bath with Ar bubbling. Finally, the mixture was centrifuged for $1 \mathrm{~h}$ at $3500 \mathrm{rpm}$, and the supernatant was carefully removed to leave the MXene sediment in the bottom of the tube.

To prepare $\mathrm{Nb}_{4} \mathrm{AlC}_{3}$, powders of niobium (99.9\% metals basis, 325 mesh), aluminum (99.8\% purity, 300 mesh), and carbon black (99\% purity, 300 mesh) were mixed and the synthesis was performed as previously reported. ${ }^{28}$ To prepare $\mathrm{Nb}_{4} \mathrm{C}_{3} \mathrm{~T}_{x}, 0.4 \mathrm{~g} \mathrm{Nb}_{4} \mathrm{AlC}_{3}$ powder was added to $30 \mathrm{~mL} \mathrm{HF}$ solution (aqueous, 49\%, Millipore-Sigma) and stirred at room temperature $\left(20-25^{\circ} \mathrm{C}\right)$ for 6 days. The produced acidic mixture was washed by DI water followed by centrifugation ( $3500 \mathrm{rpm}, 2$ min per cycle). After each centrifugation cycle, the supernatant was discarded and the sediment was dispersed in DI water until neutral $\mathrm{pH}(\sim 7)$ was reached. In order to delaminate the $\mathrm{Nb}_{4} \mathrm{C}_{3} \mathrm{~T}_{x}, 1 \mathrm{~mL}$ of TMAOH $\left(25 \%\right.$ in $\mathrm{H}_{2} \mathrm{O}$, MilliporeSigma) was mixed with $9 \mathrm{~mL} \mathrm{DI} \mathrm{H}_{2} \mathrm{O}$, added to $\mathrm{Nb}_{4} \mathrm{C}_{3} \mathrm{~T}_{x}$, and shaken for 15 minutes at room temperature. The excess TMAOH was separated from the product by repeated centrifugation at $3500 \mathrm{rpm}$. 
Diffraction. X-ray diffraction $(\mathrm{XRD})$ patterns were recorded in reflection mode under sample rotation on a PANalytical Empyrean diffractometer with a Cu K $\alpha(1.540598 \AA+1.544426 \AA)$ X-ray source.

Solid-state NMR Spectroscopy. ${ }^{1} \mathrm{H},{ }^{13} \mathrm{C}$ and ${ }^{19} \mathrm{~F}$ spectra were recorded at $11.75 \mathrm{~T} .{ }^{1} \mathrm{H}$ and ${ }^{19} \mathrm{~F}$ spectra were recorded with a Hahn echo pulse sequence, or by taking the isotropic slice of a magic angle turning, phase adjusted spinning sideband (MATPASS) sideband-separation experiment. ${ }^{40} \mathrm{H}$ and ${ }^{19} \mathrm{~F}$ experiments were performed at $50 \mathrm{kHz}$ MAS in a $1.3 \mathrm{~mm} \mathrm{HX}$ probe with recycle delays of $15 \mathrm{~s}$ and $0.3 \mathrm{~s}$, respectively. ${ }^{13} \mathrm{C}$ spectra were recorded in a $2.5 \mathrm{~mm} \mathrm{HX}$ probe at $25 \mathrm{kHz}$ MAS, with a $1 \mathrm{~s}$ recycle delay and a Hahn echo pulse sequence; the MAX samples were diluted with $20 \mathrm{wt} \%$ boron nitride to facilitate spinning (of these metallic samples). ${ }^{1} \mathrm{H} /{ }^{93} \mathrm{Nb}$ and ${ }^{19} \mathrm{~F} /{ }^{93} \mathrm{Nb}$ TRAPDOR experiments were performed at $25 \mathrm{kHz}$ with a 2.5 mm HX probe and a recycle delay of $1 \mathrm{~s} .{ }^{1} \mathrm{H} /{ }^{19} \mathrm{~F}$ HECTOR experiments were performed at 20 $\mathrm{kHz}$ with a $2.5 \mathrm{~mm} \mathrm{HX}$ probe with recycle delays of $1 \mathrm{~s}$ or $3 \mathrm{~s} .{ }^{27} \mathrm{Al}$ and ${ }^{93} \mathrm{Nb}$ spectra were recorded at $16.4 \mathrm{~T}$ with a $1.3 \mathrm{~mm}$ or $4.0 \mathrm{~mm} \mathrm{HXY}$ probe under static or MAS conditions with a single pulse or a Hahn echo pulse sequence and a recycle delay of $0.3-100 \mathrm{~s}$ for ${ }^{27} \mathrm{Al}$ and $0.1-$ $0.5 \mathrm{~s}$ for ${ }^{93} \mathrm{Nb}$, as described in each figure. Broad static ${ }^{93} \mathrm{Nb}$ spectra were collected with the assistance of an external automatic tuning/matching (eATM) $\operatorname{robot}^{41}$. These variable-offset cumulative spectra (VOCS) measurements were recorded in steps of $170 \mathrm{kHz}(\sim 1000 \mathrm{ppm})$. ${ }^{47,49} \mathrm{Ti}$ spectra were recorded with a CPMG pulse sequence using VOCS acquisition in steps of $80 \mathrm{kHz}(\sim 2000 \mathrm{ppm})$ with 115 echoes of $0.8 \mathrm{~ms}$ each and recycle delays of $0.1 \mathrm{~s}$; the subspectra were combined by taking the skyline projection: ${ }^{42}$ for each point, the highest intensity value from the overlapping sub-spectra is taken, rather than adding their intensities together. ${ }^{1} \mathrm{H}$ spectra were referenced to adamantane at $1.81 \mathrm{ppm},{ }^{13} \mathrm{C}$ spectra to the tertiary carbon of adamantane at $38.5 \mathrm{ppm},{ }^{19} \mathrm{~F}$ spectra to $\mathrm{LiF}$ at $-203 \mathrm{ppm},{ }^{27} \mathrm{Al}$ spectra to $\mathrm{AlF}_{3}$ at $-15 \mathrm{ppm},{ }^{93} \mathrm{Nb}$ spectra to $\mathrm{LiNbO}_{3}$ at $-1004 \mathrm{ppm}^{43}$, and ${ }^{47 / 49} \mathrm{Ti}$ spectra to the ${ }^{49} \mathrm{Ti}$ signal of $\mathrm{SrTiO}_{3}$ at $-843 \mathrm{ppm}$. 
The isotropic shift $\delta_{\text {iso }}$ is defined in the Haeberlen convention $\delta_{i s o}=\frac{\delta_{X X}+\delta_{Y Y}+\delta_{Z Z}}{3}$ with the chemical shift anisotropy (CSA) defined as $C S A=\delta_{Z Z}-\delta_{i s o}$ and the shift asymmetry $\eta_{\mathrm{CSA}}$ defined as $\eta_{C S A}=\frac{\delta_{Y Y}-\delta_{X X}}{\delta_{Z Z}-\delta_{i s o}}$. With these definitions, the principal components of the shift tensor are ordered such that $\left|\delta_{\mathrm{ZZ}}-\delta_{\text {iso }}\right| \geq\left|\delta_{\mathrm{XX}}-\delta_{\text {iso }}\right| \geq\left|\delta_{\mathrm{YY}}-\delta_{\text {iso }}\right| . N . b$. This definition of CSA is sometimes referred to as the reduced anisotropy, which is equal to $2 / 3$ of the 'full' anisotropy $\delta_{z Z}-$ $\frac{\delta_{X X}+\delta_{Y Y}}{2}$ used by some authors and programs. The quadrupolar coupling constant, $C_{\mathrm{Q}}$, is defined by the nuclear quadrupole moment $Q\left(Q_{\mathrm{Nb}-93}=32(2) \mathrm{fm}^{2} ; Q_{\mathrm{Al}-27}=14.66(10) \mathrm{fm}^{2}\right)^{44}$ and the largest principal component $V_{\mathrm{ZZ}}$ of the EFG at the nucleus according to $C_{Q}=\frac{e Q V_{Z Z}}{h}$ where $e$ is the electric charge and $h$ is Planck's constant. The quadrupolar asymmetry parameter $\eta_{\mathrm{Q}}$ is also defined by the EFG tensor components as $\eta_{Q}=\frac{V_{X X}-V_{Y Y}}{V_{Z Z}}$ ordered such that $\left|V_{\mathrm{ZZ}}\right| \geq\left|V_{\mathrm{YY}}\right| \geq\left|V_{\mathrm{XX}}\right|$. Calculations. Density functional theory (DFT) calculations were performed with the CASTEP planewave pseudopotential code. ${ }^{36}$ The calculations used the Perdew-Burke-Ernzerhof (PBE) exchange-correlation functiona ${ }^{37}$ and Vanderbilt ultrasoft pseudopotentials. ${ }^{38}$ MAX crystal structures from the Inorganic Crystal Structure Database were used as starting models (ICSD606236 for $\mathrm{Nb}_{2} \mathrm{AlC}$ and ICSD160755 for $\mathrm{Nb}_{4} \mathrm{AlC}_{3}$ ). Prior to the EFG calculations, atomic positions were optimized (with lattice parameters held constant) until the force on any atom was smaller than $10 \mathrm{meV} \cdot \AA^{-1}$. All calculations used a planewave energy cut-off energy of $600 \mathrm{eV}$ and a Monkhorst-Pack ${ }^{39}$ grid with a spacing finer than $2 \pi \times 0.04 \AA^{-1}$ to sample the Brillouin zone. Computed EFG parameters were used as the starting point to fit the experimental ${ }^{27} \mathrm{Al}$ and ${ }^{93} \mathrm{Nb}$ spectra.

\section{Results and Discussion}

MAX bulk structure characterization. $\mathrm{XRD}$ analysis of the $\mathrm{Nb}_{2} \mathrm{AlC}$ sample (Figure $\mathrm{S} 1$ ) showed $\mathrm{Nb}_{4} \mathrm{AlC}_{3}$ as a minor ( $\sim 5 \%$ from Rietveld refinement) secondary phase. No additional 
peaks were visible beyond those of the two MAX phases. The $\mathrm{Nb}_{4} \mathrm{AlC}_{3}$ diffraction pattern showed a NbC-like impurity $(\sim 8 \%)$ and a small, broad unindexed peak just above the background signal at $26.7^{\circ}$; no $\mathrm{Nb}_{2} \mathrm{AlC}$ was detected in the $\mathrm{Nb}_{4} \mathrm{AlC}_{3}$ sample.

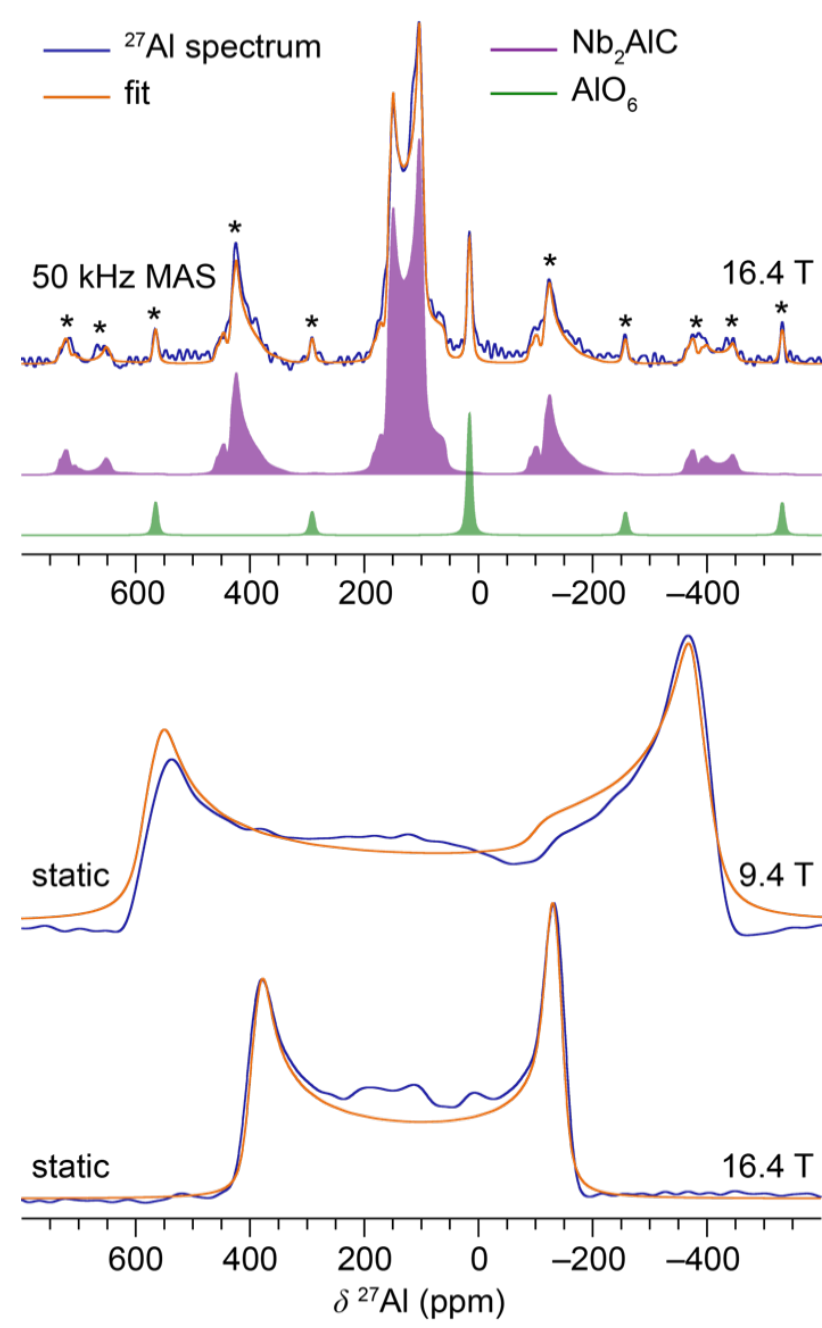

Figure $2-{ }^{27} \mathrm{Al}$ NMR spectra of $\mathrm{Nb}_{2} \mathrm{AlC}$ at $50 \mathrm{kHz}$ MAS (top) and static (bottom). MAS rate and magnetic field are given for each spectrum. The recycle delays were $100 \mathrm{~s}$ and $0.35 \mathrm{~s}$ for the MAS and static spectra, respectively. The static spectra were $T_{1}$-filtered to facilitate efficient recording of the fast-relaxing MAX signal whereas the MAS spectrum was recorded under quantitative conditions to observe all aluminum environments. Spinning sidebands are denoted with asterisks. See Table 2 for fitting parameters.

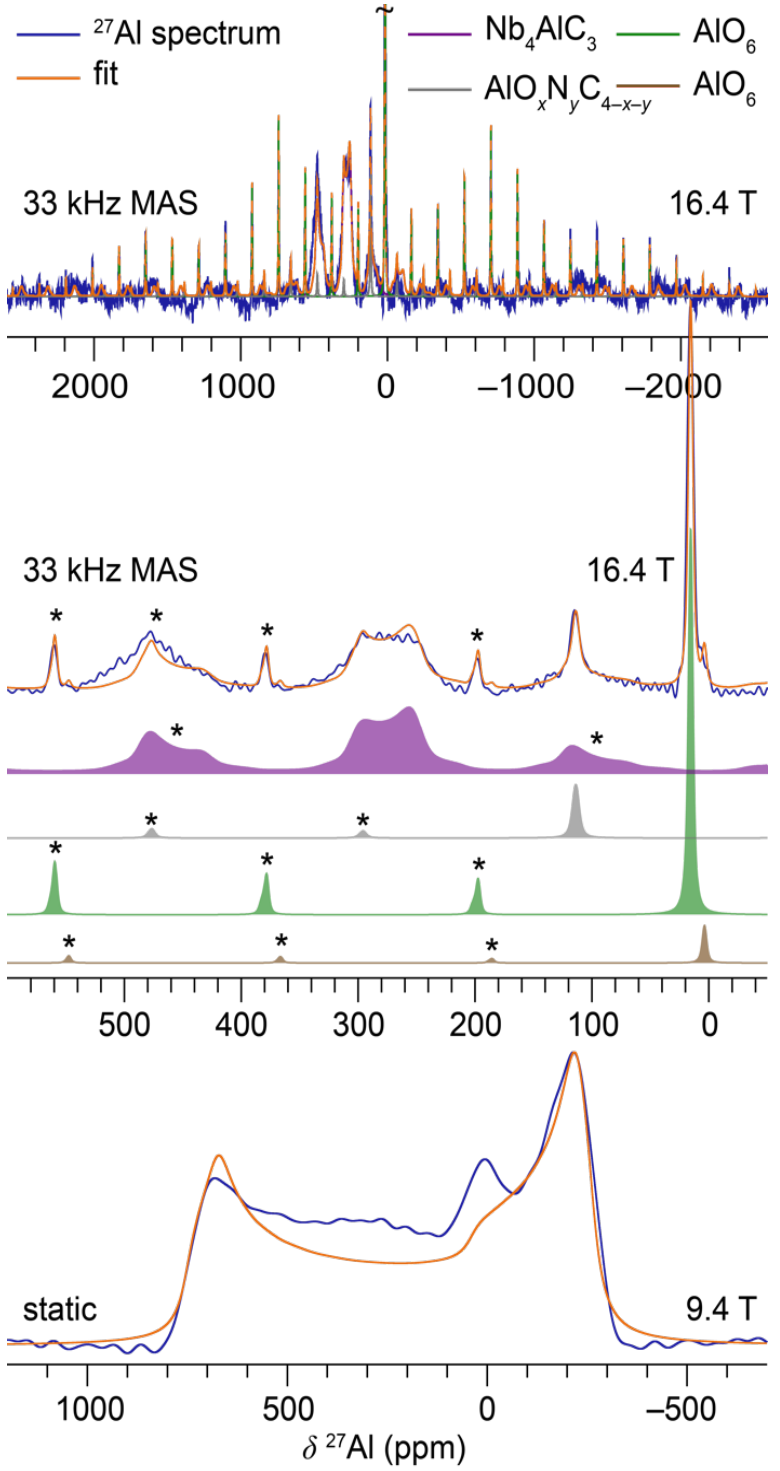

Figure $3-{ }^{27} \mathrm{Al} \mathrm{NMR}$ spectra of $\mathrm{Nb}_{4} \mathrm{AlC}_{3}$ at $33 \mathrm{kHz}$ MAS (top, middle) and static (bottom). Note the different $x$-axis scales. MAS rate and magnetic field are given for each spectrum. The recycle delays were $90 \mathrm{~s}$ and $0.05 \mathrm{~s}$ for the MAS and static spectra, respectively. Spinning sidebands are denoted with asterisks. See Table 2 for fitting parameters. The missing intensity in the fit of the static spectrum is ascribed to the $\mathrm{AlO}_{6}$ environment at $\sim 16 \mathrm{ppm}$.

${ }^{27} \mathrm{Al}$ NMR spectra of the MAX phases $\mathrm{Nb}_{2} \mathrm{AlC}$ and $\mathrm{Nb}_{4} \mathrm{AlC}_{3}$ are given in Figures 2 and 3 , respectively. For each compound, a simultaneous fit was performed over the static and MAS 
spectra (Table 2). The DFT calculated quadrupolar parameters served as useful starting points to guide the fits (Table 2). Static spectra were sensitive to the value of the CSA while MAS removed CSA broadening and resulted in spectra that were more sensitive to the isotropic shift and quadrupolar tensor. The positions of discontinuities in the powder lineshape from satellite transitions, where observed, were also used to determine the quadrupolar parameters. The calculated quadrupolar coupling constants matched the experimental values to within $<5 \%$.

In addition to aluminum in the MAX phases, ${ }^{27} \mathrm{Al}$ NMR revealed the presence of secondary phases. At short recycle delays, the MAX phases, with fast spin-lattice, $T_{1}$, nuclear

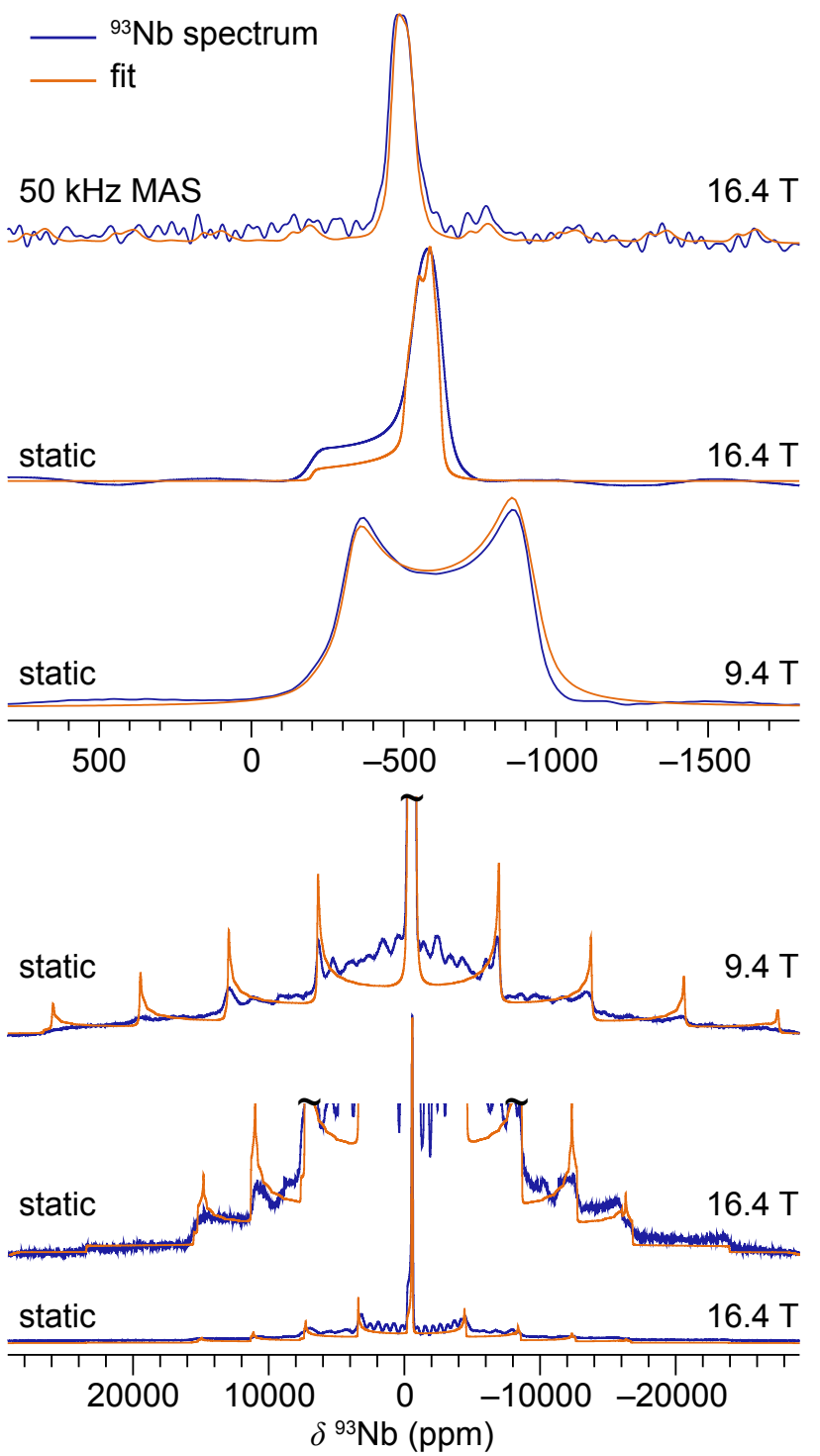

Figure $4-{ }^{93} \mathrm{Nb} \mathrm{NMR}$ spectra of $\mathrm{Nb}_{2} \mathrm{AlC}$. MAS rate and magnetic field are given for each spectrum. See Table 2 for fitting parameters. relaxation from conduction electrons, appear relatively pure (Figure S2-3).

6.4 T However, at longer free induction decay (FID) intervals, the relative intensities of the impurities increase; an indication that the impurities are diamagnetic with longer $T_{1}$ relaxation times. The $\mathrm{Nb}_{2} \mathrm{AlC}$ sample exhibits an unexpected resonance at 16 ppm while the $\mathrm{Nb}_{4} \mathrm{AlC}_{3}$ sample shows three additional ${ }^{27} \mathrm{Al}$ resonances at ca. 5, 17, and $115 \mathrm{ppm}$. The largest impurity in both samples is ascribed to octahedral $\mathrm{AlO}_{6}$ environments as found in corundum alumina, ${ }^{45}$ on the basis of the shift $(16-17$ ppm), $C_{\mathrm{Q}}$ (ca. $2.4 \mathrm{MHz}$, upper limit $\leq 4$ $\mathrm{MHz})$ and $T_{1}$ relaxation time $(18 \mathrm{~s})$. The $\mathrm{Nb}_{4} \mathrm{AlC}_{3}$ sample signal at $5 \mathrm{ppm}$ is also 
consistent with octahedral $\mathrm{AlO}_{6}$, as found in e.g. boehmite, gibbsite, or $\gamma$-alumina. ${ }^{46}$ The oxide environments could arise from secondary oxide phases, or from the oxide layers previously observed by XPS to form on the surface of MAX particles. ${ }^{47}$ The resonance at $115 \mathrm{ppm}$ appears at a higher frequency than for typical aluminum oxides or fluorides ${ }^{48}$; it does coincide with the shift range of aluminum carbide $\mathrm{Al}_{4} \mathrm{C}_{3}(111-120 \mathrm{ppm})$ but the maximum $C_{\mathrm{Q}}$ value for the observed resonance is ca. $4.5 \mathrm{MHz}$ while $\mathrm{Al}_{4} \mathrm{C}_{3}$ has two $\mathrm{Al}$ sites with $C_{\mathrm{Q}}$ magnitudes of 14-17 MHz. ${ }^{49,50}$ Hayes et al. identified aluminum oxycarbide impurities with smaller $C_{\mathrm{Q}} \mathrm{s}$ in their recent study of commercial $\mathrm{Al}_{4} \mathrm{C}_{3}$ so a related aluminum species is plausible here. ${ }^{50}$ Another possibility is the tetrahedral aluminum nitride environment that appears at around 110-115 ppm in AlN and in aluminum oxynitrides with a $C_{\mathrm{Q}}$ of a few $\mathrm{MHz}$, consistent with the resonance observed here. ${ }^{51-54}$ Note that the ${ }^{27} \mathrm{Al}$ signal from $\mathrm{Nb}_{2} \mathrm{AlC}$ covers a range of $\sim 90-$ $170 \mathrm{ppm}$, so the impurity at $115 \mathrm{ppm}$ is less pronounced but it can be clearly seen as a shoulder that appears as the interval between scans increases (Figure S2). Quantitative spectra recorded with recycle delays of $90-100 \mathrm{~s}$ (Figure S2) revealed the relative ratios of the MAX and impurity (or surface) species in the samples from the perspective of aluminum content. ${ }^{47}$ For the $\mathrm{Nb}_{2} \mathrm{AlC}$ sample, a ratio of 89:9:2 was found for the MAX signal at $169 \mathrm{ppm}$ and the impurity resonances at 16 and $115 \mathrm{ppm}$, respectively. For the $\mathrm{Nb}_{4} \mathrm{AlC}_{3}$ sample, a ratio of 56:34:7:3 was found for the MAX signal at $319 \mathrm{ppm}$ and the impurity resonances at 17,5 , and 115 ppm, respectively.

Table 2 - Experimental (shift and quadrupolar) and calculated (quadrupolar only) NMR parameters of $\mathrm{Nb}_{2} \mathrm{AlC}$ and $\mathrm{Nb}_{4} \mathrm{AlC}_{3}{ }^{\mathrm{a}}{ }^{\mathrm{a}}$

\begin{tabular}{|c|c|c|c|c|c|c|c|c|c|}
\hline \multirow{2}{*}{ Phase } & \multirow{2}{*}{ Site } & \multirow{2}{*}{$\delta_{\text {iso }}(\mathrm{ppm})$} & \multirow{2}{*}{ CSA } & \multirow{2}{*}{$\eta \operatorname{CsA}$} & \multicolumn{2}{|c|}{$\mathrm{C}_{\mathrm{Q}}(\mathrm{MHz})$} & \multicolumn{2}{|c|}{$\eta_{\mathrm{Q}}$} & \multirow{2}{*}{$\begin{array}{l}\text { Euler angles } \\
\qquad \beta\left(^{\circ}\right)^{\mathrm{c}}\end{array}$} \\
\hline & & & & & Exp. & Calc. ${ }^{b}$ & Exp. & Calc. & \\
\hline \multirow{3}{*}{$\mathrm{Nb}_{2} \mathrm{AlC}$} & $\mathrm{Nb1}$ & $-475(10)^{d}$ & $280(50)$ & $0.1(1)$ & $32.3(3)$ & -30.8 & $0.01(1)$ & 0.00 & $5(2)$ \\
\hline & $\mathrm{Al} 1$ & $171(2)$ & $-275(20)$ & $0.2(1)$ & $15.7(2)$ & -16.0 & $0.05(5)$ & 0.00 & $2(5)$ \\
\hline & C1 & 293(1) & $\mathrm{n} / \mathrm{d}$ & $\mathrm{n} / \mathrm{d}$ & & & & & \\
\hline \multirow{2}{*}{$\mathrm{Nb}_{4} \mathrm{AlC}_{3}$} & $\mathrm{Nb} 1$ & $-1700(5)$ & $300(200)$ & $0.0(1)$ & $2(1)$ & 2.5 & $\mathrm{n} / \mathrm{d}$ & 0.00 & $\mathrm{n} / \mathrm{d}$ \\
\hline & $\mathrm{Nb} 2$ & $-840(20)$ & $650(200)$ & $0.0(1)$ & $32(5)$ & -33.5 & $0.00(5)$ & 0.00 & $80(10)$ \\
\hline
\end{tabular}




\begin{tabular}{ccccccccc}
\hline Al1 & $319(2)$ & $-280(10)$ & $0.4(2)$ & $15.6(2)$ & -16.0 & $0.10(10)$ & 0.00 & $0(5)$ \\
C1 & $238(2)$ & $\mathrm{n} / \mathrm{d}$ & $\mathrm{n} / \mathrm{d}$ & & & & & \\
$\mathrm{C} 2$ & $324(2)$ & $\mathrm{n} / \mathrm{d}$ & $\mathrm{n} / \mathrm{d}$ & & & & & \\
\hline
\end{tabular}

${ }^{\mathrm{a}}$ Static and magic angle spinning spectra (in some cases at multiple fields) were fit to a single model. Estimated errors in the last digit are given in parentheses, derived from lineshape fitting.

${ }^{\mathrm{b}}$ The sign of the quadrupolar coupling can be calculated but is not determined experimentally from the spectrum of a polycrystalline sample.

${ }^{\mathrm{c}}$ The fits are only sensitive to the $\beta$ angle because $\eta$ is nearly zero.

${ }^{\mathrm{d}}$ The isotropic shift is temperature-dependent and thus varies with MAS rate. The static ${ }^{93} \mathrm{Nb}$ spectrum of $\mathrm{Nb}_{2} \mathrm{AlC}$ was fit with $-475(10) \mathrm{ppm}$ while the $50 \mathrm{kHz}$ spectrum was fit with $-445(5) \mathrm{ppm}$.

$\mathrm{n} / \mathrm{d}=$ not determined, either due to insufficient signal-to-noise $\left({ }^{13} \mathrm{C}\right)$ or because the fit was insensitive to this parameter.

Cells corresponding to the quadrupolar properties are left blank for ${ }^{13} \mathrm{C}$ because it is a $I=1 / 2$ nucleus.

Quadrupolar ${ }^{93} \mathrm{Nb}$ NMR spectra of the compounds were recorded under MAS and static conditions. A fit of the ${ }^{93} \mathrm{Nb}$ NMR data of $\mathrm{Nb}_{2} \mathrm{AlC}$ reproduced the central and satellite transitions of the spectrum (Figure 4, Table 2), with calculated and measured nuclear quadrupolar coupling constants in close agreement. The Hahn echo and quadrupolar Carr-Purcell-Meiboom-Gill (QCPMG) ${ }^{93} \mathrm{Nb}$ MAS spectra of $\mathrm{Nb}_{4} \mathrm{AlC}_{3}$ (Figure 5) showed a number of overlapping peaks that could not be resolved by variable MAS rates due to their individual linewidths (full-width at halfmaximum $(\mathrm{FWHM})>40 \mathrm{kHz})$ and the static spectrum also showed overlapping lineshapes

a) $\begin{array}{cc}\mathrm{Nb}_{4} \mathrm{AlC}_{3} & \mathrm{Nb}_{4} \mathrm{AlC} \\ \text { external Nb} & \text { internal } \mathrm{Nb}\end{array}$

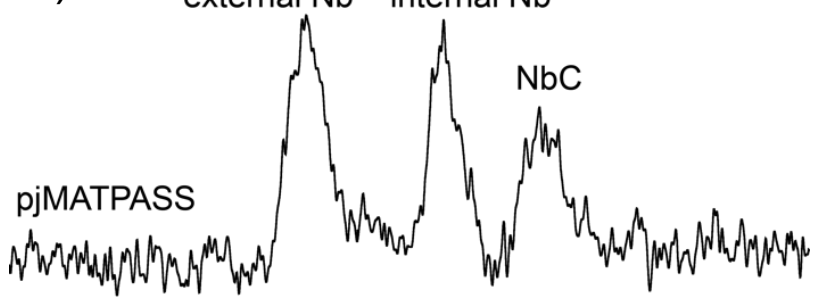

b)
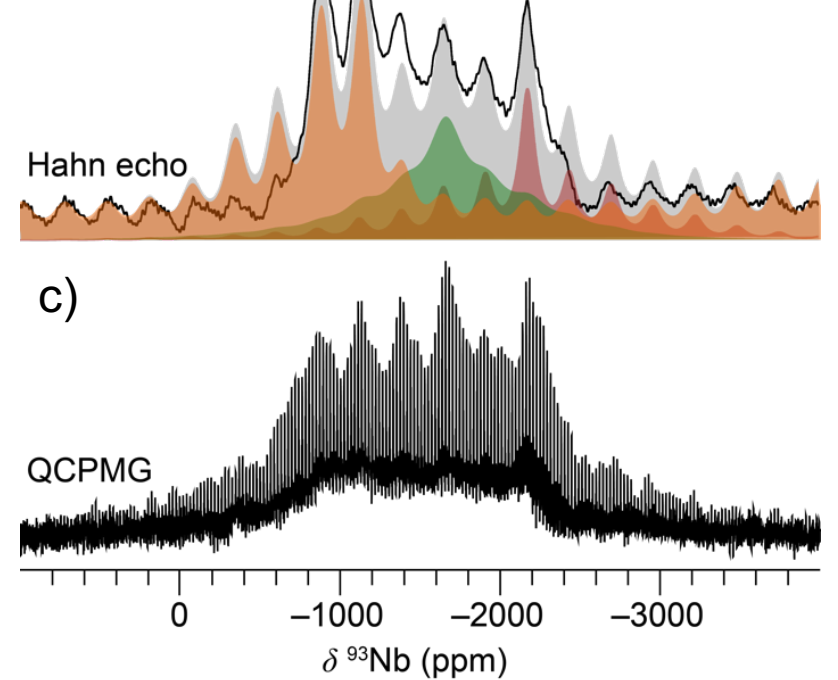

Figure $5-{ }^{9} \mathrm{Nb}$ MAS NMR spectra of the $\mathrm{Nb}_{4} \mathrm{AlC}_{3}$ sample (45 kHz MAS, 16.4 T). Several methods were used to study this sample including (a) the isotropic slice of a pjMATPASS experiment; (b) a Hahn echo- deconvoluted in grey with the internal site $\mathrm{Nb} 1$ in green, the external site $\mathrm{Nb} 2$ orange, and $\mathrm{NbC}$ in red; and (c) a QCPMG measurement.

(Figure S4). To overcome this challenge, a MATPASS experiment was performed; the isotropic slice showed three broad, featureless resonances at $-840,-1700$, and $-2340 \mathrm{ppm}$ (Figure 5). However, only two distinct $\mathrm{Nb}$ environments are expected in $\mathrm{Nb}_{4} \mathrm{AlC}_{3}$. The low 
frequency ${ }^{93} \mathrm{Nb}$ resonance matches that of $\mathrm{NbC}$ (Figure 5a,b), as do the ${ }^{13} \mathrm{C}$ NMR data (vide infra). Stoichiometric $\mathrm{NbC}$ should give a sharp ${ }^{93} \mathrm{Nb}$ signal with $C_{\mathrm{Q}}=0$ due to the cubic site symmetry of the 12 -coordinate niobium atom, however nonstoichiometry is common in $\mathrm{NbC},{ }^{55}$ depending on the preparation conditions, with $\mathrm{NbC}_{x}(0.7 \leq x<1)$ yielding quadrupolar ${ }^{93} \mathrm{Nb}$ signals. ${ }^{56,57}$ Overlapping lines preclude an accurate fitting of the quadrupolar parameters of the $\mathrm{NbC}_{x}$ impurity in $\mathrm{Nb}_{4} \mathrm{AlC}_{3}$ here but a small $C_{\mathrm{Q}}(\sim 2 \mathrm{MHz})$ improved the fit. For $\mathrm{Nb}_{2} \mathrm{SnC}$ (Figure S5), a sharp ${ }^{93} \mathrm{Nb}$ signal was observed with an isotropic shift of $-189(3) \mathrm{ppm}$; this is $300 \mathrm{ppm}$ higher frequency than the isostructural $\mathrm{Nb}_{2} \mathrm{AlC}$. In the wideline static VOCS measurement, $\mathrm{Nb}$ metal was also observed as a secondary phase at $\sim 7200 \mathrm{ppm}$. 
The ${ }^{13} \mathrm{C}$ NMR spectrum of $\mathrm{Nb}_{2} \mathrm{AlC}$ (Figure 6a, bottom) shows a single resonance at $293 \mathrm{ppm}$ corresponding to the single carbon environment in the 211 phase. The ${ }^{13} \mathrm{C}$ NMR spectrum of $\mathrm{Nb}_{4} \mathrm{AlC}_{3}$ (Figure 6b, bottom) shows two resonances at $324 \mathrm{ppm}$ and $238 \mathrm{ppm}$ corresponding to the outer $(\mathrm{C} 2)$ and inner $(\mathrm{C} 1)$ carbon sites of $\mathrm{Nb}_{4} \mathrm{AlC}_{3}$, respectively. For both

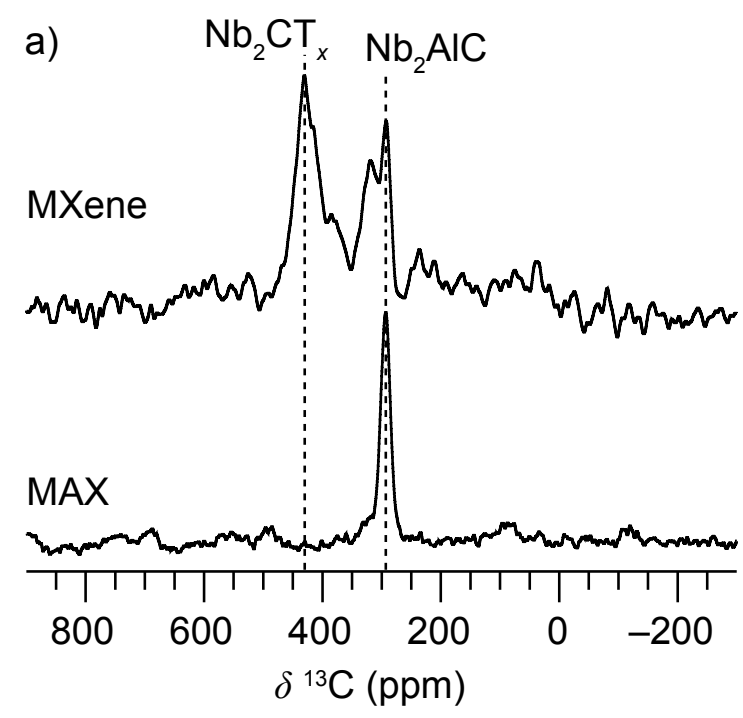

b)

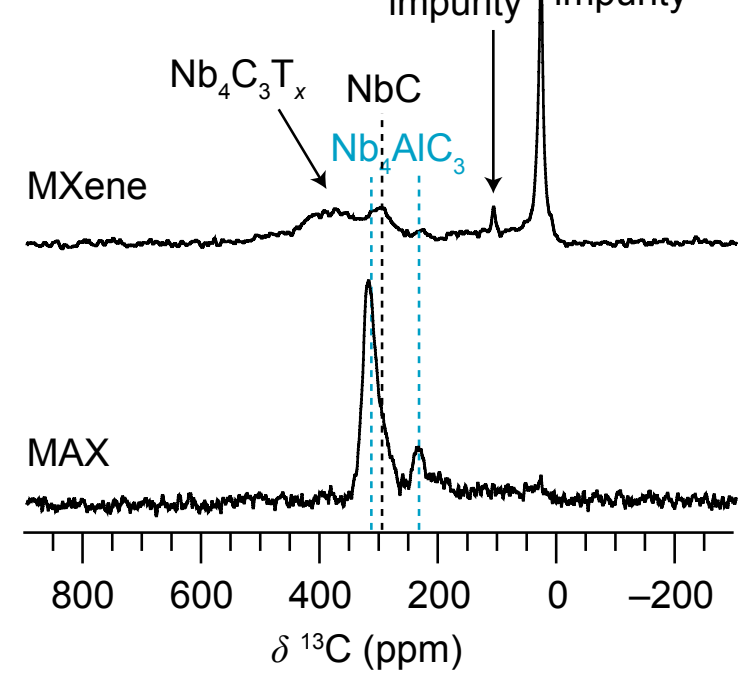

Figure $6-{ }^{13} \mathrm{C}$ NMR spectra of (a) $\mathrm{Nb}_{2} \mathrm{CT}_{x}$ MXene and $\mathrm{Nb}_{2} \mathrm{AlC}$ MAX phase and (b) $\mathrm{Nb}_{4} \mathrm{C}_{3} \mathrm{~T}_{x}$ MXene and $\mathrm{Nb}_{4} \mathrm{AlC}_{3}$ MAX phase at $25 \mathrm{kHz}$ MAS and 16.4 $\mathrm{T}$. Resonances are labeled, dashed lines are guides to the eye.
$\mathrm{Nb}$ MAX phases, the large ${ }^{13} \mathrm{C}$ shift is evidence of metallic conduction resulting in a Knight shift; the shifts are larger than observed for $\mathrm{V}_{2} \mathrm{AlC}(208 \mathrm{ppm}),{ }^{35}$ but less than for $\mathrm{Ti}_{3} \mathrm{AlC}_{2}$ $(566 \mathrm{ppm})^{36}$. There is a significant shoulder for the $324 \mathrm{ppm}$ peak which is ascribed to $\mathrm{NbC}$, the single carbon site of which resonates at $\sim 315$ ppm (Figure S6); accounting for this signal, the integrated intensities of the inner and outer carbon sites are in reasonable agreement with the expected $2: 1$ ratio. The ${ }^{13} \mathrm{C}$ and ${ }^{93} \mathrm{Nb}$ data together clearly show the presence of $\mathrm{NbC}$ in $\mathrm{Nb}_{4} \mathrm{AlC}_{3}$, although it is not observed in the $\mathrm{X}-$ ray diffraction pattern (Figure S1) because (i) it is present in nanoparticulate or amorphous form and/or (ii) its identification is obstructed by peak overlap. Note, that phases such as amorphous carbon and low levels of $\mathrm{Nb}_{2} \mathrm{O}_{5}$ would be difficult to observe via these NMR

experiments due to the broad nature of those signals and/or overlap with other signals. The presence of alumina suggests that niobia could also be present, and Sarycheva and Gogotsi 
observed amorphous carbon and titania in a degraded $\mathrm{Ti}_{3} \mathrm{C}_{2} \mathrm{~T}_{x}$ sample via Raman spectroscopy. ${ }^{58}$

\section{MXene bulk structure characterization}

By etching out the aluminum, the MAX phases were converted to MXenes. However, the $\mathrm{Nb}_{2} \mathrm{CT}_{x}$ also has a significant amount of unreacted $\mathrm{Nb}_{2} \mathrm{AlC}$, while $\mathrm{NbC}$ remains present as an impurity in $\mathrm{Nb}_{4} \mathrm{C}_{3} \mathrm{~T}_{x}$, as previously seen for other MAX/MXene samples. ${ }^{25,59}$

The ${ }^{93} \mathrm{Nb}$ NMR spectra of $\mathrm{Nb}_{2} \mathrm{CT}_{x}$ and $\mathrm{Nb}_{4} \mathrm{C}_{3} \mathrm{~T}_{x}$ are shown in Figure 7 and Figure $\mathrm{S} 7$. Since niobium atoms are located at the outer surface of the 2D MXene sheets, the number of distinct $\mathrm{Nb}$ local environments and NMR signals depends on the surface terminations. The ${ }^{93} \mathrm{Nb}$ lineshape of $\mathrm{Nb}_{2} \mathrm{CT}_{x}$ was simulated with two quadrupolar lines, providing a reasonable fit to the data (Figure 7); the minor but sharper signal is consistent with $\mathrm{Nb}_{2} \mathrm{AlC}$, the broader signal was attributed to $\mathrm{Nb}_{2} \mathrm{CT}_{x}$ and was fit with $\delta_{\text {iso }}=-790(30) \mathrm{ppm}, \mathrm{CSA}=-350(50) \mathrm{ppm}$, $\eta_{\mathrm{CSA}}=0.5(3), C_{\mathrm{Q}}=77(3) \mathrm{MHz}, \eta_{\mathrm{Q}}=0.2(1)$, Euler angles $\alpha, \beta, \gamma=0^{\circ}, 50(10)^{\circ}, 0^{\circ}$. The $C_{\mathrm{Q}}$ for $\mathrm{Nb}_{2} \mathrm{CT}_{x}$ is more than double that of $\mathrm{Nb}_{2} \mathrm{AlC}$, providing spectral evidence for the reduction of symmetry at the MXene surface. Furthermore, the non-zero $\eta_{\mathrm{Q}}$ indicates a breaking of the threefold symmetry of the $\mathrm{Nb}$ site at the surface, presumably due to the surface terminations. Calculations for a bare $\mathrm{Nb}_{2} \mathrm{C}$ surface predict a ${ }^{93} \mathrm{Nb} C_{\mathrm{Q}}$ of $122 \mathrm{MHz}$, so the lower observed $C_{\mathrm{Q}}$ is also evidence for the surface terminations which result in a more symmetric charge distribution than a bare surface. Basic ordered models for surface-terminated $\mathrm{Nb}_{2} \mathrm{CT}_{x}\left(\mathrm{~T}_{x}=\mathrm{F}_{2}\right.$, $\left.(\mathrm{OH})_{2},(\mathrm{OH}) \mathrm{F}, \mathrm{O}_{2}, \mathrm{O}\right)$ give calculated $C_{\mathrm{Q}}$ values ranging from 36-109 $\mathrm{MHz}$ (Table $\mathrm{S} 1$ ), which are consistent with the experimental $\mathrm{C}_{\mathrm{Q}}$ of $77 \mathrm{MHz}$. The best agreement is for fluoride and oxide termination, which may suggest a greater proportion of fluoride and oxide terminations than hydroxyl terminations, as previously observed for $\mathrm{Ti}_{3} \mathrm{C}_{2} \mathrm{~T}_{x} \cdot{ }^{36}$ Meanwhile, the ${ }^{93} \mathrm{Nb}$ lineshape of $\mathrm{Nb}_{4} \mathrm{C}_{3} \mathrm{~T}_{x}$ is substantially broader. An exact fitting of the lineshape could not be 
obtained due to the difficulty of distinguishing a potential distribution of surface terminations, the two $\mathrm{Nb}$ sites in $\mathrm{Nb}_{4} \mathrm{C}_{3} \mathrm{~T}_{x}$, and the $\mathrm{NbC}_{x}$ impurity, which all overlap. Nevertheless, based on the linewidth a maximum $C_{\mathrm{Q}}$ of $\sim 100 \mathrm{MHz}$ can be determined, ruling out a significant proportion of bare surface (calculated $C_{\mathrm{Q}}=135 \mathrm{MHz}$ for the outer $\mathrm{Nb} 2$ site, Table $\mathrm{S} 2$ ). Given
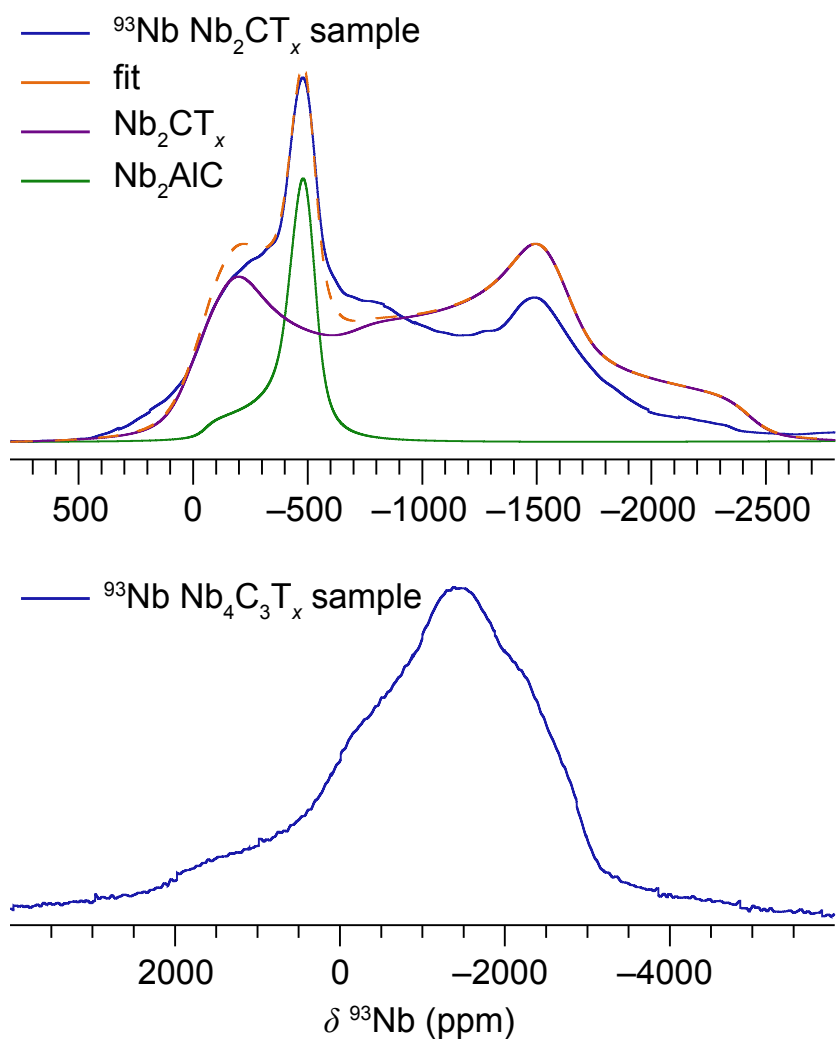

Figure 7 - Static ${ }^{93} \mathrm{Nb} \mathrm{NMR}$ central transition spectra of the $\mathrm{Nb}_{2} \mathrm{CT}_{x}$ and $\mathrm{Nb}_{4} \mathrm{C}_{3} \mathrm{~T}_{x}$ samples at $16.4 \mathrm{~T}$. For $\mathrm{Nb}_{2} \mathrm{CT}_{x}$, the deconvolution into signals from $\mathrm{Nb}_{2} \mathrm{CT}_{x}$ and $\mathrm{Nb}_{2} \mathrm{AlC}$ is shown. For full VOCS spectra, see Figure S7. that the calculated quadrupolar parameters for ordered models of surface terminations (Table S2) are in the range 15-70 MHz, chemical shift dispersion and anisotropy of the different $\mathrm{Nb}$ environments must make a large contribution to the experimental linewidth.

In the ${ }^{13} \mathrm{C}$ NMR spectra of etched $\mathrm{Nb}_{2} \mathrm{AlC}$, a new signal can be seen at 430 ppm due to $\mathrm{Nb}_{2} \mathrm{CT}_{x}$ MXene, although there is also still unreacted $\mathrm{Nb}_{2} \mathrm{AlC}$ present (Figure 6a, top). The intensity in the ${ }^{13} \mathrm{C}$ spectrum between the $\mathrm{Nb}_{2} \mathrm{AlC}$

and $\mathrm{Nb}_{2} \mathrm{CT}_{x}$ resonances may correspond to partially etched regions with carbon environments intermediate between the MAX and MXene, e.g. regions with a MAX-like aluminum layer on one side, but terminations on the other, or nanoscale clusters of unetched aluminum. After etching $\mathrm{Nb}_{4} \mathrm{AlC}_{3}$ (Figure $6 \mathrm{~b}$, top), a broad high frequency signal can be observed at $\sim 400 \mathrm{ppm}$, corresponding to $\mathrm{Nb}_{4} \mathrm{C}_{3} \mathrm{~T}_{x}$ MXene, although the inner and outer carbon sites cannot be resolved. After etching, the $\mathrm{NbC}$ impurity is still evident, as well as signals from other impurities in the sample at 31 and $111 \mathrm{ppm}$; the former is correlated with a ${ }^{1} \mathrm{H}$ signal at $1 \mathrm{ppm}$ 
in the ${ }^{1} \mathrm{H} \rightarrow{ }^{13} \mathrm{C}$ HETCOR spectrum (Figure S8c), suggesting that this impurity is predominantly alkyl, while the latter can be observed in a ${ }^{19} \mathrm{~F} \rightarrow{ }^{13} \mathrm{C}$ cross polarization $(\mathrm{CP})$ experiment (Figure $\mathrm{S} 8 \mathrm{~b}$ ), which, combined with the chemical shift, suggests a $-\mathrm{CF}_{2}-$ moiety in a fluorinated organic species. Notably, the ${ }^{13} \mathrm{C}$ shift increases on etching from the MAX to the MXene for both $\mathrm{Nb}_{2} \mathrm{CT}_{x}$ and $\mathrm{Nb}_{4} \mathrm{C}_{3} \mathrm{~T}_{x}$; this is due to an increased Knight shift, corresponding to an increased density of states at the Fermi level for the carbon atoms in the MXene phases. The same increase in ${ }^{13} \mathrm{C}$ shift was observed for $\mathrm{V}_{2} \mathrm{CT}_{x}$ (from $208 \mathrm{ppm}$ to $260 \mathrm{ppm}$ ), ${ }^{35}$ however, in contrast, the ${ }^{13} \mathrm{C}$ Knight shift actually decreases for $\mathrm{Ti}_{3} \mathrm{C}_{2} \mathrm{~T}_{x}$ (from $566 \mathrm{ppm}$ to $380-410 \mathrm{ppm}$ ) ${ }^{36}$. As seen from the presence of the $\mathrm{Nb}_{2} \mathrm{AlC}$ MAX signal in the ${ }^{93} \mathrm{Nb},{ }^{27} \mathrm{Al}$, and ${ }^{13} \mathrm{C}$ spectra, not all aluminum had been etched out during the HF treatment, consistent with prior work on other MXenes: $\mathrm{V}_{2} \mathrm{AlC}$ was observed in $\mathrm{V}_{2} \mathrm{CT}_{x}$ samples and $\mathrm{Ti}_{3} \mathrm{AlC}_{2}$ in $\mathrm{Ti}_{3} \mathrm{C}_{2} \mathrm{~T}_{x}$ samples in their respective ${ }^{13} \mathrm{C}$ NMR spectra. ${ }^{35,36}$ The ${ }^{27} \mathrm{Al}$ NMR spectra of the MXene samples (Figure S9) also show an $\mathrm{AlO}_{6}$-like aluminum oxide environment, while the $\mathrm{Nb}_{2} \mathrm{CT}_{x}$ sample also shows a signal consistent with $\mathrm{AlF}_{3} \cdot n \mathrm{H}_{2} \mathrm{O}$, a common impurity in $\mathrm{MXenes}^{60}$ and one that can be readily identified with NMR spectroscopy.

Since diffraction did not reveal the Al-O, Al-F, or Al- $(\mathrm{C}, \mathrm{N}, \mathrm{O})$ compounds identified here, these secondary phases must be amorphous, present as small nanoparticles, or hidden under the MAX/MXene diffraction peaks. These findings again highlight that the picture from diffraction alone can be misleading. Furthermore, $\mathrm{NbC}_{x}$ was almost entirely hidden under the $\mathrm{Nb}_{4} \mathrm{AlC}_{3} \mathrm{XRD}$ peaks. A method that is sensitive to amorphous phases such as solid-state NMR and/or quantitative diffraction with an internal standard should be routinely performed to characterize MAX and MXene phases.

Surface terminations of $\mathbf{N b}_{4} \mathbf{C}_{3} \mathbf{T}_{x}$ and $\mathbf{N b}_{2} \mathbf{C} \mathbf{T}_{x} \cdot{ }^{1} \mathrm{H}$ and ${ }^{19} \mathrm{~F}$ NMR spectra were recorded in order to investigate the surface functionalization of the MXene phases directly. The ${ }^{1} \mathrm{H}$ NMR 
spectrum of $\mathrm{Nb}_{2} \mathrm{CT}_{x}$ as synthesized shows a large signal at $6.3 \mathrm{ppm}$ due to free $\mathrm{H}_{2} \mathrm{O}$ as well as two resonances at large chemical shifts of 19.5 and $26.0 \mathrm{ppm}$ (Figure 8a); these latter signals are assigned to $-\mathrm{OH}$ surface terminations. $-\mathrm{OH}$ terminations were observed in the MXenes $\mathrm{V}_{2} \mathrm{CT}_{x}$ at 85 and $27 \mathrm{ppm}^{35}$ and $\mathrm{Ti}_{3} \mathrm{C}_{2} \mathrm{~T}_{x}$ between 12.5 and $20 \mathrm{ppm}$, the exact shift values depending on the synthesis procedure ${ }^{36,37}$. The free $\mathrm{H}_{2} \mathrm{O}$ signal can be reduced by drying the MXene at $200{ }^{\circ} \mathrm{C}$ in vacuo (Figure $8 \mathrm{~b}$ ), after which an additional resonance can be distinguished at $12.2 \mathrm{ppm}$, as well as sharper signals between -0.5 and $1.6 \mathrm{ppm}$; the former could be due to a further $-\mathrm{OH}$ termination environment, or bound $\mathrm{H}_{2} \mathrm{O}$ partaking in strong hydrogen bonding, while the latter are assigned to intercalated volatile contaminants, as was also observed for $\mathrm{Ti}_{3} \mathrm{C}_{2} \mathrm{~T}_{x}$. There is also a loss of intensity for the $26.0 \mathrm{ppm}$ signal in particular, which may be due to loss of $-\mathrm{OH}$ terminations as $\mathrm{H}_{2} \mathrm{O}$ during the drying process. ${ }^{61}$ 


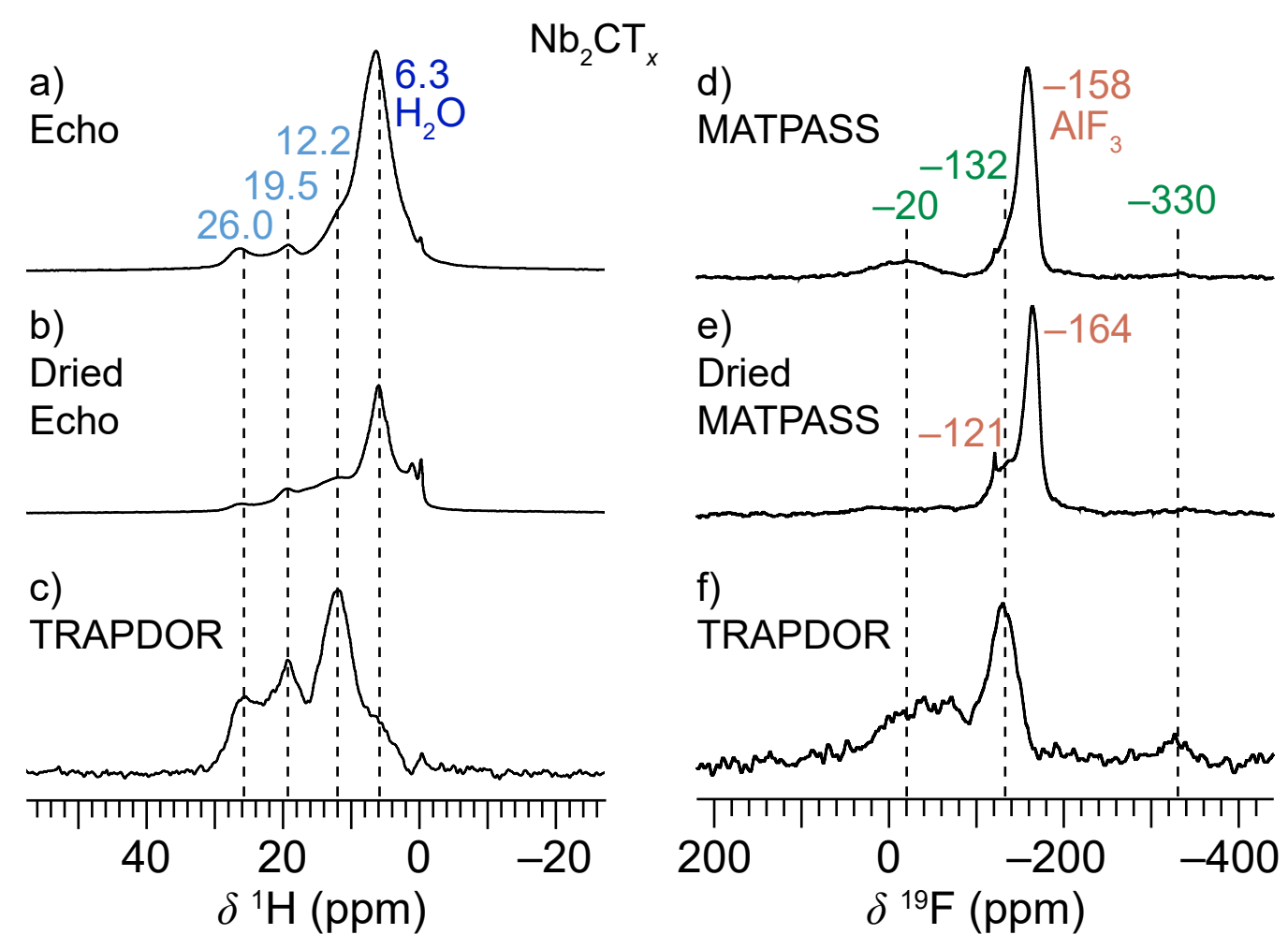

$\mathrm{Nb}_{4} \mathrm{C}_{3} \mathrm{~T}_{x}$

g)

Echo

Organic imp.

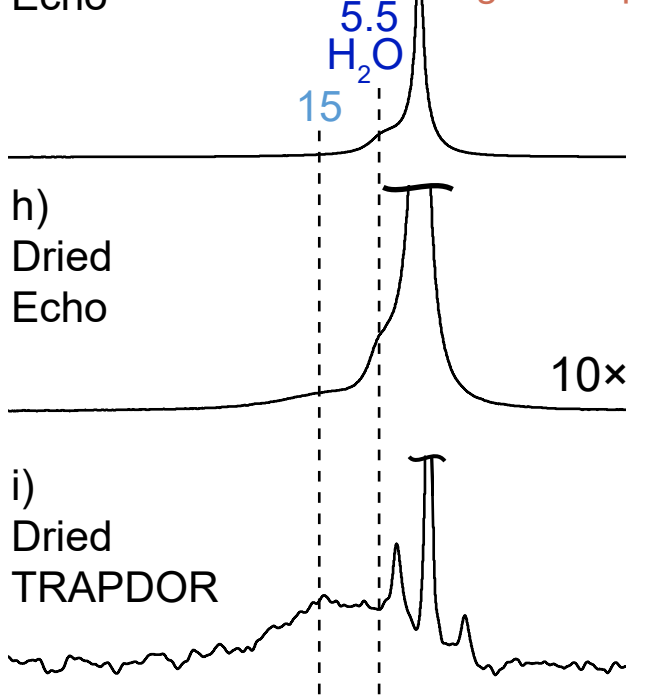

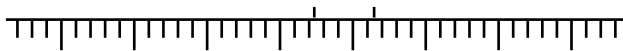

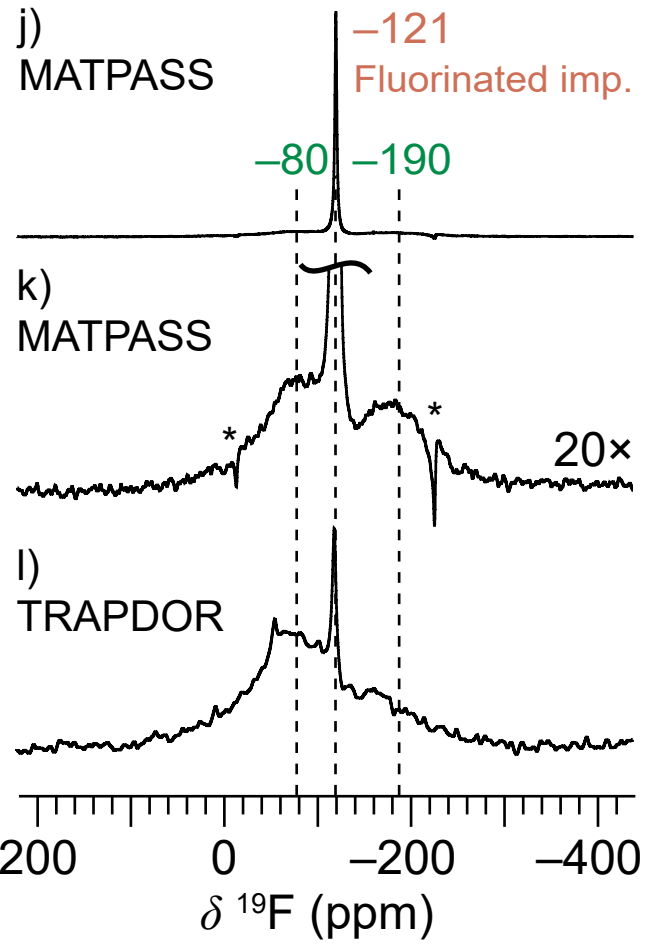

Figure $8-{ }^{1} \mathrm{H}$ and ${ }^{19} \mathrm{~F}$ NMR spectra of $\mathrm{Nb}_{2} \mathrm{CT} x(\mathrm{a}-\mathrm{f})$ and $\mathrm{Nb}_{4} \mathrm{C}_{3} \mathrm{~T}_{x}(\mathrm{~g}-\mathrm{l})$. The ${ }^{1} \mathrm{H} /{ }^{93} \mathrm{Nb}$ and ${ }^{19} \mathrm{~F} /{ }^{93} \mathrm{Nb}$ TRAPDOR difference spectra $(\mathrm{c}, \mathrm{f}, \mathrm{i}, \mathrm{l})$ show ${ }^{1} \mathrm{H}(\mathrm{c}, \mathrm{i})$ or ${ }^{19} \mathrm{~F}(\mathrm{f}, \mathrm{l})$ atoms near ${ }^{93} \mathrm{Nb}$ atoms. The echo and MATPASS experiments were performed at $50 \mathrm{kHz}$ MAS and the TRAPDOR experiments at $30 \mathrm{kHz}$, all at a magnetic field strength of $11.7 \mathrm{~T}$. Sidebands are marked with asterisks. 
The assignment of the ${ }^{1} \mathrm{H}$ NMR resonances at high chemical shift to surface species on the MXene layers can be confirmed by ${ }^{1} \mathrm{H} /{ }^{93} \mathrm{Nb}$ TRAPDOR experiments: ${ }^{62}$ for these spectra, a ${ }^{1} \mathrm{H}$ spin echo is recorded with continuous irradiation of ${ }^{93} \mathrm{Nb}$ during only the first half of the echo, thus any dephasing due to recoupled ${ }^{1} \mathrm{H}-{ }^{93} \mathrm{Nb}$ interactions is only partially refocused, resulting in a loss of signal intensity for ${ }^{1} \mathrm{H}$ environments in the vicinity of ${ }^{93} \mathrm{Nb}$; when the difference is taken between spin echoes recorded with and without ${ }^{93} \mathrm{Nb}$ irradiation, these ${ }^{1} \mathrm{H}$ environments (near ${ }^{93} \mathrm{Nb}$ ) can be selectively observed. The signals at $12.2,19.5$ and $26.0 \mathrm{ppm}$ can all be clearly observed in the TRAPDOR difference spectra (Figure 8c and Figure S10), confirming their vicinity to $\mathrm{Nb}$ atoms at the MXene surface; the signals at less than $5 \mathrm{ppm}$, on the other hand, are suppressed in the TRAPDOR difference spectra. A weaker TRAPDOR effect is observed for the free $\mathrm{H}_{2} \mathrm{O}$ resonance at $6.3 \mathrm{ppm}$, which suggests that only some of the free $\mathrm{H}_{2} \mathrm{O}$ is proximal to $\mathrm{Nb}$ and/or that it is mobile; this may be evidence of chemisorbed water, as proposed by Persson et al. ${ }^{63}$

The sideband-separated ${ }^{19} \mathrm{~F}$ NMR spectrum of $\mathrm{Nb}_{2} \mathrm{CT}_{x}$, recorded with a MATPASS pulse sequence, ${ }^{40}$ shows a number of different resonances (Figure $8 \mathrm{~d}$ ). The signal at $-158 \mathrm{ppm}$ is due to $\mathrm{AlF}_{3} \cdot n \mathrm{H}_{2} \mathrm{O}$, a by-product of the etching process also seen in the ${ }^{27} \mathrm{Al}$ spectrum (Figure $\mathrm{S} 8) ;{ }^{36,64}$ this resonance is suppressed in the ${ }^{19} \mathrm{~F} /{ }^{93} \mathrm{Nb}$ TRAPDOR difference spectrum (Figure 8f), leaving the signals at $-20,-132$ and $-330 \mathrm{ppm}$, which must be near $\mathrm{Nb} .{ }^{1} \mathrm{H} /{ }^{19} \mathrm{~F}$ HETCOR experiments (Figure S11) are completely dominated by the $\mathrm{H}_{2} \mathrm{O} \leftrightarrow \mathrm{AlF}_{3}$ correlation, so cannot be used to aid assignment of the ${ }^{19} \mathrm{~F}$ spectrum. After drying at $200{ }^{\circ} \mathrm{C}$ in vacuo the $\mathrm{AlF}_{3} \cdot n \mathrm{H}_{2} \mathrm{O}$ resonance shifts to $-164 \mathrm{ppm}$ due to changes in hydration, so that the $-132 \mathrm{ppm}$ signal can be seen as a shoulder more clearly, and there is also a small, sharp peak at $-121 \mathrm{ppm}$ from a fluorinated organic impurity. The ${ }^{19} \mathrm{~F}$ signal at $-20 \mathrm{ppm}$ is largely removed by drying, so may be tentatively ascribed to $-\mathrm{F}$ terminations with strong hydrogen bonding to $\mathrm{H}_{2} \mathrm{O}$ molecules, or adjacent $-\mathrm{OH}$ terminations (given that the intensity of the $-\mathrm{OH}$ signals in the ${ }^{1} \mathrm{H}$ NMR also 
decreases on drying). Conversely, the major ${ }^{19} \mathrm{~F}$ signal at $-132 \mathrm{ppm}$ is assigned to $-\mathrm{F}$ terminations without strong $\mathrm{H}$ bonding. The minor signal at $-330 \mathrm{ppm}$ is strongly ionic; it may be a niobium fluoride species formed as a byproduct from excessive etching and could therefore be minimized by using milder etching conditions. ${ }^{65}$

The ${ }^{1} \mathrm{H}$ NMR spectrum of $\mathrm{Nb}_{4} \mathrm{C}_{3} \mathrm{~T}_{x}$ (Figure $8 \mathrm{~g}$ ) is dominated by a peak at $1.0 \mathrm{ppm}$ due to the organic impurity identified from the ${ }^{1} \mathrm{H} \rightarrow{ }^{13} \mathrm{C}$ HETCOR experiment (Figure S8c). Further ${ }^{1} \mathrm{H}$ signals at $5.5 \mathrm{ppm}$ and $15 \mathrm{ppm}$ are assigned to $\mathrm{H}_{2} \mathrm{O}$ and $-\mathrm{OH}$ terminations, respectively. Both the organic contaminant and the $\mathrm{H}_{2} \mathrm{O}$ signals can be reduced by drying in vacuo at $200{ }^{\circ} \mathrm{C}$ overnight (Figure $8 \mathrm{~h}$ ), while the $-\mathrm{OH}$ terminations can be identified in the ${ }^{1} \mathrm{H} /{ }^{93} \mathrm{Nb}$ TRAPDOR difference spectrum (Figure 8i and Figure S10). In the TRAPDOR experiment, the $1.0 \mathrm{ppm}$ peak is almost, but not entirely, suppressed; the residual signal and satellite peaks are due to the differential phase (Bloch-Siegert) shift ${ }^{66,67}$ introduced by ${ }^{93} \mathrm{Nb}$ irradiation, which results in imperfect cancellation in the difference spectrum.

The ${ }^{19} \mathrm{~F}$ MATPASS NMR spectrum for $\mathrm{Nb}_{4} \mathrm{C}_{3} \mathrm{~T}_{x}$ is dominated by a resonance at -121 ppm (Figure 8j,k), which is consistent with the fluorinated impurity identified by ${ }^{19} \mathrm{~F} \rightarrow{ }^{13} \mathrm{C} \mathrm{CP}$. Two other signals can also be distinguished, centered at ca. -190 and $-80 \mathrm{ppm}$; these are assigned to $-\mathrm{F}$ terminations as they can clearly be observed in the ${ }^{19} \mathrm{~F} /{ }^{93} \mathrm{Nb}$ TRAPDOR difference spectrum (Figure 81), although the sidebands of the terminal $-\mathrm{F}$ signals are unresolved. Further evidence for the assignment of the $-\mathrm{OH}$ and $-\mathrm{F}$ terminations can be seen in the ${ }^{1} \mathrm{H} /{ }^{19} \mathrm{~F}$ HETCOR spectra: in the ${ }^{19} \mathrm{~F} \rightarrow{ }^{1} \mathrm{H}$ spectrum (Figure 9b) a broad correlation is observed between both the $\mathrm{H}_{2} \mathrm{O}(6.0 \mathrm{ppm})$ and $-\mathrm{OH}(15 \mathrm{ppm}){ }^{1} \mathrm{H}$ resonances and ${ }^{19} \mathrm{~F}$ intensity between ca. 50 and $-300 \mathrm{ppm}$ that corresponds to the signals from $-\mathrm{F}$ terminations at -190 and $-80 \mathrm{ppm}$, with unresolved spinning sidebands. This supports the assignments of the ${ }^{1} \mathrm{H}$ and ${ }^{19} \mathrm{~F}$ spectra, as well as showing that the terminations are intimately mixed, rather than being 
segregated into different regions, as also found for $\mathrm{Ti}_{3} \mathrm{C}_{2} \mathrm{~T}_{x} \cdot{ }^{36} \mathrm{In}$ contrast, the ${ }^{1} \mathrm{H} \rightarrow{ }^{19} \mathrm{~F}$ spectrum

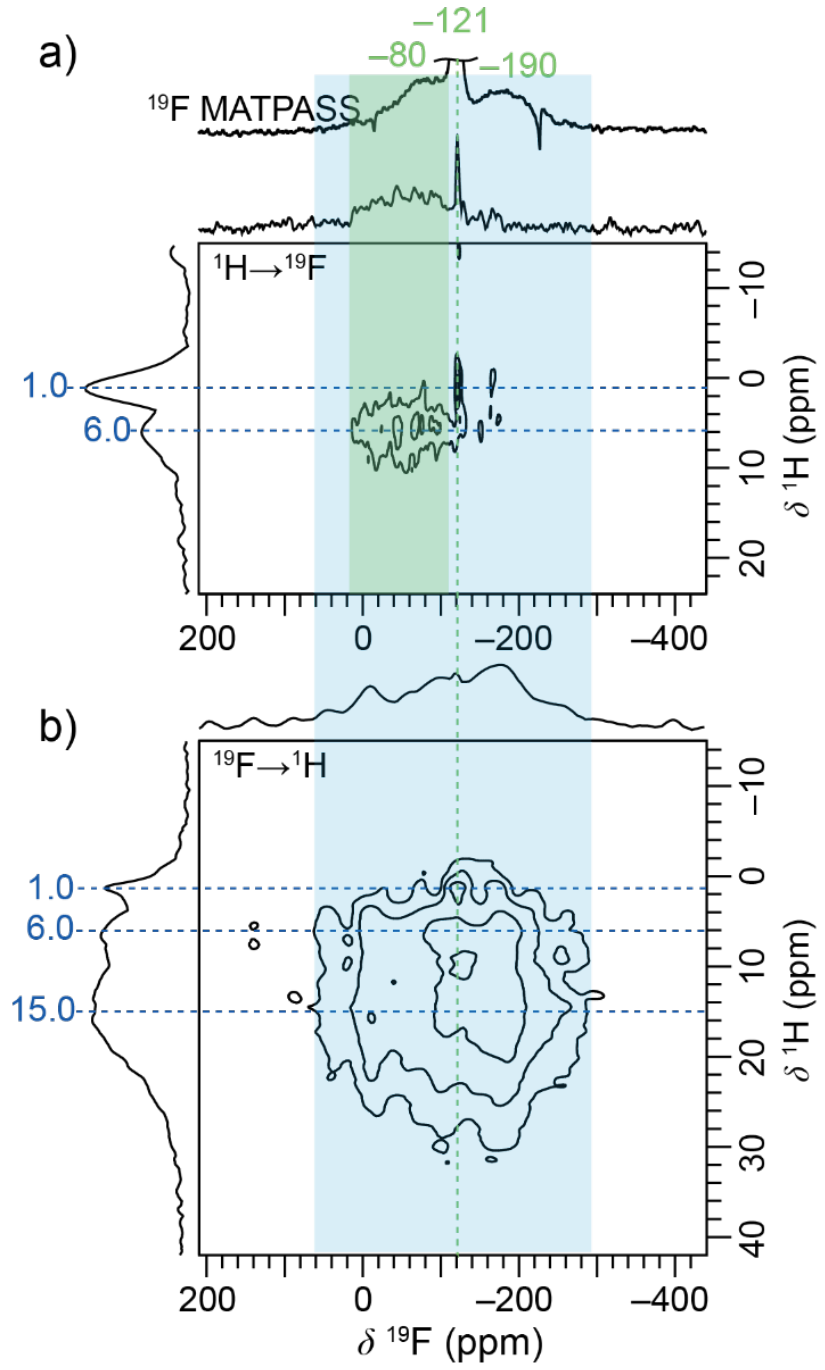

Figure 9: ${ }^{1} \mathrm{H} /{ }^{19} \mathrm{~F}$ HETCOR spectra of $\mathrm{Nb}_{4} \mathrm{C}_{3} \mathrm{~T}_{x}$ recorded at $11.7 \mathrm{~T}$ and $20 \mathrm{kHz}$ MAS with a $2 \mathrm{~ms}$ contact time. The recycle delays were $3 \mathrm{~s}$ and $1 \mathrm{~s}$ respectively for a) and $b$ ). The ${ }^{19} \mathrm{~F}$ MATPASS spectrum is shown for comparison. Note that the axes for $b$ ) have been swapped relative to convention to allow comparison of the ${ }^{19} \mathrm{~F}$ axis.
(Figure 9a) only shows correlation between the ${ }^{1} \mathrm{H} \mathrm{H}_{2} \mathrm{O}(6.0 \mathrm{ppm})$ signal and the $-80 \mathrm{ppm}-\mathrm{F}$ termination ${ }^{19} \mathrm{~F}$ signal. The lack of signal from the $-\mathrm{OH}$ terminations is ascribed to a short ${ }^{1} \mathrm{H} \quad T_{1 \rho}$ for this resonance, so that the transverse magnetization decays before developing significant cross polarization. The fact that the $\mathrm{H}_{2} \mathrm{O}$ resonance correlates only with the $-80 \mathrm{ppm}{ }^{19} \mathrm{~F}$ signal suggests that these $-\mathrm{F}$ termination environments are associated with interlayer water via hydrogen bonding, whereas those at $-190 \mathrm{ppm}$ are not. The higher frequency ${ }^{19} \mathrm{~F}$ shift observed for $\mathrm{H}$-bonded $-\mathrm{F}$ terminations in $\mathrm{Nb}_{4} \mathrm{C}_{3} \mathrm{~T}_{x}$ is also consistent with the assignment of the $-20 \mathrm{ppm}{ }^{19} \mathrm{~F}$ signal in $\mathrm{Nb}_{2} \mathrm{CT}_{x}$ to strongly H-bonded $-\mathrm{F}$

terminations.

Table 3 shows a comparison of the shifts of the observed surface species for the different MXenes studied by ${ }^{1} \mathrm{H}$ and ${ }^{19} \mathrm{~F}$ NMR to date. For the $-\mathrm{OH}$ terminations, $\mathrm{V}_{2} \mathrm{CT}_{x}$ is the exception with an extremely large shift of $85 \mathrm{ppm}$; this is due to a metallic Knight shift, as confirmed by the short $T_{1}$ relaxation of this signal, ${ }^{35}$ Interestingly, the $-\mathrm{F}$ terminations of $\mathrm{V}_{2} \mathrm{CT}_{x}$ do not appear to be significantly Knight shifted and are observed at a similar frequency to those 
of $\mathrm{Ti}_{3} \mathrm{C}_{2} \mathrm{~T}_{x}$. The $-\mathrm{OH}{ }^{1} \mathrm{H}$ shifts obtained for $\mathrm{Ti}_{3} \mathrm{C}_{2} \mathrm{~T}_{x}$ have been shown by both Hope et al. ${ }^{36}$ and Anayee et al. ${ }^{37}$ to depend on the synthesis procedure, but in both cases fall in the range 12.5$20 \mathrm{ppm}$. In contrast, Kobayashi et al. ${ }^{38}$ observed no ${ }^{1} \mathrm{H}$ signals at frequencies above $7 \mathrm{ppm}$, instead ascribing signals at $0.5-2.0$ and $3.6 \mathrm{ppm}$ to $-\mathrm{OH}$ terminations on the basis of DFT calculations and the assignment of a $\mathrm{Ti}_{2} \mathrm{CT}_{x}{ }^{1} \mathrm{H}$ spectrum in a separate report by Sugahara ${ }^{68}$. These differences may be due to sample preparation, however, we note that the studies of Kobayashi et al. and Sugahara et al. do not provide direct evidence for their terminal $-\mathrm{OH}$ assignments (c.f. the ${ }^{1} \mathrm{H}-{ }^{13} \mathrm{C}$ HETCOR employed for $\mathrm{V}_{2} \mathrm{CT}_{x}$ and $\mathrm{Ti}_{3} \mathrm{CT}_{\mathrm{x}},{ }^{35,36}$ and the ${ }^{1} \mathrm{H}\left\{{ }^{93} \mathrm{Nb}\right\}$ TRAPDOR used here). Furthermore, (i) Sugahara et al. found an estimated composition of $\mathrm{Ti}_{2} \mathrm{C}(\mathrm{OH})_{0.3} \mathrm{O}_{0.7} \mathrm{~F}_{0.6} \mathrm{Cl}_{0.4}$ with a similar etching procedure to Kobayashi et al. (LiF, HCl) ${ }^{68}$ and (ii) $\mathrm{Ti}_{3} \mathrm{C}_{2} \mathrm{~T}_{x}$ is electronically conducting (so much so that the sample in the Kobayashi et al. study was diluted by a factor of 20 to perform magic angle spinning) but the DFT calculations for $-\mathrm{OH}$ shifts include neither $-\mathrm{F}$ termination nor Knight shift contributions, which are expected to substantially affect the ${ }^{1} \mathrm{H}$ shifts. ${ }^{38}$ It is possible that due to the high conductivity of their samples, Kobayashi et al. and Sugahara et al. are not able to observe the $-\mathrm{OH}$ terminations due to rf penetration or bulk magnetic susceptibility broadening effects.

The $-\mathrm{OH}{ }^{1} \mathrm{H}$ shifts for the $\mathrm{Nb}$ MXenes are similar to those observed for $\mathrm{Ti}_{3} \mathrm{C}_{2} \mathrm{~T}_{x}$ by Hope et al. ${ }^{36}$ and Anayee et al. ${ }^{37}$, although as the $26 \mathrm{ppm}$ signal for $\mathrm{Nb}_{2} \mathrm{CT}_{x}$ is outside the diamagnetic range for ${ }^{1} \mathrm{H} \mathrm{NMR}$, there must also be at least a small Knight shift, as for $\mathrm{V}_{2} \mathrm{CT}_{x}$. The $-\mathrm{F}$ terminations, on the other hand, are observed at higher frequencies for the $\mathrm{Nb} \mathrm{MXenes}$ than for $\mathrm{V}_{2} \mathrm{CT}_{x}$ and $\mathrm{Ti}_{3} \mathrm{C}_{2} \mathrm{~T}_{x}$, which could be due to more covalent $\mathrm{Nb}-\mathrm{F}$ bonding caused by the more diffuse $4 d$ orbitals. In general, the multiple NMR signals observed for $-\mathrm{OH}$ and $-\mathrm{F}$ terminations, and the dependence on the synthesis, can be ascribed to distinct local environments due to different arrangements of the surface terminations $(-\mathrm{OH},-\mathrm{O},-\mathrm{F}$ and 
termination vacancy), as well as interlayer $\mathrm{H}_{2} \mathrm{O}$, as shown, for instance, for the $-\mathrm{F}$ terminations in $\mathrm{Nb}_{4} \mathrm{C}_{3} \mathrm{~T}_{x}$.

Table 3 - Summary of the chemical shifts of ${ }^{1} \mathrm{H}$ and ${ }^{19} \mathrm{~F}$ surface species observed for different MXenes.

\begin{tabular}{cccc}
\hline \hline Phase & Source & $\delta^{1} \mathrm{H} / \mathrm{ppm}$ & $\delta^{19} \mathrm{~F} / \mathrm{ppm}$ \\
\hline $\mathrm{Nb}_{2} \mathrm{CT}_{x}$ & This work & $12.2,19.5,26.0$ & $-20,-132$ \\
$\mathrm{Nb}_{4} \mathrm{C}_{3} \mathrm{~T}_{x}$ & This work & 15.0 & $-80,-190$ \\
$\mathrm{~V}_{2} \mathrm{CT}_{x}$ & Harris et al. $^{35}$ & 27,85 & -265 \\
$\mathrm{Ti}_{3} \mathrm{C}_{2} \mathrm{~T}_{x}$ & Hope et al. $^{36}$ & $12.5 / 18.6^{\mathrm{a}}$ & $-227 /-255^{\mathrm{a}}$ \\
& Anayee et al. ${ }^{37}$ & $15 / 20^{\mathrm{a}}$ & Not attempted \\
& Kobayashi et & $0.5-2.0,3.6$ & "Unable to \\
& al. ${ }^{38}$ & & observe"38 \\
\hline
\end{tabular}

${ }^{a}$ Depending on the synthesis procedure

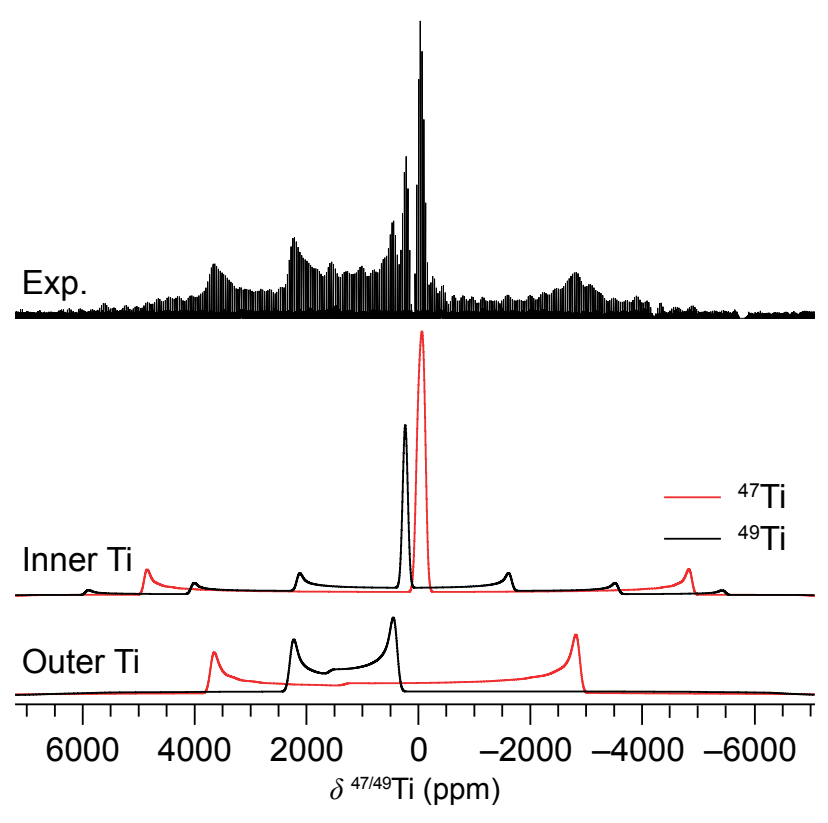

Figure $10-{ }^{47 / 49} \mathrm{Ti}$ static QCPMG spectrum of $\mathrm{Ti}_{3} \mathrm{AlC}_{2}$ acquired at $16.4 \mathrm{~T}$ by taking the skyline projection of five VOCS sub-spectra. The simulated quadrupolar ${ }^{47} \mathrm{Ti}$ and ${ }^{49} \mathrm{Ti}$ patterns for the inner and outer Ti sites are shown below the experimental spectrum. Simulation parameters are given in Table 4.

\section{Extending the transition-metal NMR of}

MAX phases. Based on insights gained from the ${ }^{93} \mathrm{Nb} \mathrm{NMR}$ of $\mathrm{Nb}$ MAX phases, we were also able to interpret the ${ }^{47 / 49} \mathrm{Ti}$ NMR of $\mathrm{Ti}_{3} \mathrm{AlC}_{2}$, another technologically important MAX phase used as a high temperature ceramic, and the precursor to the most studied MXene phase, $\mathrm{Ti}_{3} \mathrm{C}_{2} \mathrm{~T}_{x}{ }^{69,5,7} \mathrm{Ti}$ NMR is particularly challenging to interpret because its two NMR-active isotopes, ${ }^{47} \mathrm{Ti}$ and ${ }^{49} \mathrm{Ti}$, are both quadrupolar $(I=5 / 2$ and $7 / 2$, respectively) and by chance have extremely similar gyromagnetic ratios, differing by only 267 ppm $(0.027 \%)$. As a result, overlapping quadrupolar lineshapes for both isotopes are typically observed in a single spectrum. ${ }^{46,70,71}$ Nevertheless, the ${ }^{47} \mathrm{Ti}$ and ${ }^{49} \mathrm{Ti}$ signals of both the inner 
and outer Ti environments in $\mathrm{Ti}_{3} \mathrm{AlC}_{2}$ could be assigned from the overlapped spectrum (Figure 10) by considering that the $C_{\mathrm{Q}}$ values for the outer/inner metal sites are expected to differ by an order-of-magnitude (c.f. ${ }^{93} \mathrm{Nb}$ in $\mathrm{Nb}_{4} \mathrm{AlC}_{3}$ ), and by using the fixed relationships between the nuclear properties of ${ }^{47 / 49} \mathrm{Ti}$. The quadrupolar parameters of the two titanium sites for both nuclei are given in Table 4: since the frequency separation and ratio of the quadrupolar coupling constants for the ${ }^{47} \mathrm{Ti}$ and ${ }^{49} \mathrm{Ti}$ signals are fixed by their respective nuclear properties, there are fewer independent parameters than it might seem, and the simultaneous agreement of both signals with the measured spectrum affords a high confidence in the NMR parameters. As also observed for the $\mathrm{Nb}$ MAX phases (Table 2), the Ti sites exhibit axial quadrupolar tensors, consistent with the crystallographic symmetry, while the inner site has a modest $C_{\mathrm{Q}}$ relative to the outer site.

Table 4 - Fitted ${ }^{47} \mathrm{Ti}$ and ${ }^{49} \mathrm{Ti}$ quadrupolar parameters for the two crystallographic Ti sites in $\mathrm{Ti}_{3} \mathrm{AlC}_{2}$ extracted from Figure 10. The estimated errors in the last digit are given in parentheses. Note that the simulated spectra were insensitive to the CSA parameters, which were therefore not determined.

\begin{tabular}{lcccc}
\hline \hline Site & Nucleus & $\delta_{\text {iso }}(\mathrm{ppm})^{\mathrm{a}}$ & $\mathrm{C}_{\mathrm{Q}}(\mathrm{MHz})$ & $\eta \mathrm{Q}$ \\
\hline \multirow{2}{*}{ Inner } & ${ }^{47} \mathrm{Ti}$ & $-27(10)$ & $2.57^{\mathrm{b}}$ & $0.00^{\mathrm{c}}$ \\
& ${ }^{49} \mathrm{Ti}$ & $239(10)$ & $2.10^{\mathrm{b}}$ & $0.00^{\mathrm{c}}$ \\
\multirow{2}{*}{ Outer } & ${ }^{47} \mathrm{Ti}$ & $1338(20)$ & $18.1(3)$ & $0.00(5)$ \\
& ${ }^{49} \mathrm{Ti}$ & $1604(20)$ & $14.8(2)$ & $0.00(5)$ \\
\hline \hline
\end{tabular}

${ }^{\mathrm{a}} \mathrm{The}{ }^{47} \mathrm{Ti}$ shifts are referenced to ${ }^{49} \mathrm{Ti}$ and as such are $266 \mathrm{ppm}$ less than the corresponding ${ }^{49} \mathrm{Ti}$ shift, rather than equal.

${ }^{\mathrm{b}}$ This represents an upper bound, based on the linewidth of the ${ }^{47} \mathrm{Ti}$ signal.

${ }^{\mathrm{c}}$ The inherent linewidth is too broad to determine $\eta$ from the lineshape of the central transition, and the turning points of the satellite transitions cannot be identified, however $\eta=0$ is consistent with the crystallographic symmetry.

\section{Conclusions}

An extensive survey of the NMR properties of the Nb MAX and MXene phases has been presented. The multinuclear approach adopted in this study provides complementary measurements of the local structural and electronic properties of the MAX and MXene phases, identifies the nature and connectivity of MXene surface terminating species, and enables unambiguous detection of a number of impurity phases. 
${ }^{27} \mathrm{Al}$ and ${ }^{93} \mathrm{Nb} \mathrm{NMR}$ spectra of the MAX phases $\mathrm{Nb}_{2} \mathrm{AlC}$ and $\mathrm{Nb}_{4} \mathrm{AlC}_{3}$ have been recorded under static and MAS conditions with high resolution and wideline techniques, allowing extraction of the full anisotropic shift and quadrupolar tensors. The insights gained from the $\mathrm{Nb}$ MAX phases also then enabled the interpretation of the ${ }^{47 / 49} \mathrm{Ti}$ spectrum of $\mathrm{Ti}_{3} \mathrm{AlC}_{2}$. The quadrupolar parameters extracted from the spectra were in close agreement with DFT calculations, affording a detailed view of the local coordination environments. The ${ }^{27} \mathrm{Al}$, ${ }^{93} \mathrm{Nb}$ and ${ }^{13} \mathrm{C}$ spectra also reveal impurity phases in both $\mathrm{Nb}_{2} \mathrm{AlC}$ and $\mathrm{Nb}_{4} \mathrm{AlC}_{3}$, including aluminium oxide, hydrated aluminium fluoride, aluminium carbide/oxycarbide/nitride, niobium metal, and (possibly nonstoichiometric) $\mathrm{NbC}_{x}$ species. Many of these impurities are not apparent from diffraction alone and these results should serve as a guide for future synthesis efforts.

Following the etching process, the conversion to form MXenes was confirmed by ${ }^{13} \mathrm{C}$ $\mathrm{NMR}$, although the presence of unreacted $\mathrm{Nb}_{2} \mathrm{AlC}$ is apparent in the ${ }^{93} \mathrm{Nb},{ }^{27} \mathrm{Al}$, and ${ }^{13} \mathrm{C}$ spectra of the $\mathrm{Nb}_{2} \mathrm{CT}_{x}$ sample. ${ }^{93} \mathrm{Nb}$ environments become notably more asymmetric in the MXenes, demonstrating the reduction of symmetry at the surface. The quadrupolar coupling is still lower than calculated for a bare surface, however, pointing to the presence of surface terminations; these surface terminations are key in determining the performance of MXenes in various applications. $-\mathrm{OH}$ and $-\mathrm{F}$ terminations have been identified for both $\mathrm{Nb}_{2} \mathrm{CT}_{x}$ and $\mathrm{Nb}_{4} \mathrm{C}_{3} \mathrm{~T}_{x}$ in the ${ }^{1} \mathrm{H}$ and ${ }^{19} \mathrm{~F}$ NMR spectra, their proximity to the surface demonstrated with ${ }^{93} \mathrm{Nb}$ TRAPDOR experiments, and a comparison made with previous studies on $\mathrm{Ti}_{3} \mathrm{C}_{2} \mathrm{~T}_{x}$ and $\mathrm{V}_{2} \mathrm{CT}_{x}$ MXenes. The atomic-scale intermixing of $-\mathrm{OH}$ and $-\mathrm{F}$ terminations for $\mathrm{Nb}_{4} \mathrm{C}_{3} \mathrm{~T}_{x}$ is seen in the ${ }^{1} \mathrm{H} /{ }^{19} \mathrm{~F}$ HETCOR spectra, which would be challenging to identify by other techniques, and the different ${ }^{19} \mathrm{~F}$ termination environments observed for both MXenes are correlated with the degree of hydrogen bonding to interlayer $\mathrm{H}_{2} \mathrm{O}$. 
The structural insights derived here should serve as a basis to improve synthetic methods and to guide more in-depth computational modelling, both for the Nb MAX and MXene phases, as well as to facilitate comparisons with the wider family of materials. The nature of the surface terminations and interlayer water in MXenes are key to understanding the functional properties, while further insight into the electronic structure in the MAX phases is of fundamental interest. In this way, structure-property relationships can be developed and both MAX and MXene materials can be optimized for advanced functional applications.

\section{Associated Content}

Supplementary information file containing diffraction data; additional NMR spectra of $\mathrm{Nb}_{4} \mathrm{AlC}_{3}, \mathrm{Nb}_{2} \mathrm{AlC}, \mathrm{Nb}_{4} \mathrm{C}_{3} \mathrm{~T}_{x}, \mathrm{Nb}_{2} \mathrm{CT}_{x}, \mathrm{Nb}_{2} \mathrm{SnC}$, and $\mathrm{NbC}$; tables of ${ }^{93} \mathrm{Nb}$ quadrupolar parameters for bare and terminated $\mathrm{Nb}$ MXene surfaces.

\section{Author Information}

\section{Corresponding Author}

Email: cpg27@cam.ac.uk

\section{Notes}

The authors declare no competing financial interest.

\section{Acknowledgements}

K.J.G. thanks the Winston Churchill Foundation of the United States and the Herchel Smith Scholarship for financial support. M.A.H. acknowledges funding from the Oppenheimer foundation. K.J.G. and C.P.G. are grateful for support from the EPSRC (EP/M009521/1). M. A. was supported by the National Science Foundation Graduate Research Fellowship under Grant DGE-1646737. Y. G. was supported by the National Science Foundation under grant number DMR-1740795. This work made use of the IMSERC X-ray and NMR facility at 
Northwestern University, which has received support from the National Science Foundation (NSF DMR-0521267), the Soft and Hybrid Nanotechnology Experimental (SHyNE) Resource (NSF ECCS-1542205), the State of Illinois, and the International Institute for Nanotechnology (IIN). Any opinions, findings, and conclusions or recommendations expressed in this material are those of the authors and do not necessarily reflect the views of the National Science Foundation. The authors are grateful to M. Alhabeb and Dr. D. Pinto (Drexel University) for their help with the synthesis of samples for this study.

\section{References}

(1) Sun, Z. M. Progress in Research and Development on MAX Phases: A Family of Layered Ternary Compounds. Int. Mater. Rev. 2011, 56 (3), 143-166. https://doi.org/10.1179/1743280410Y.0000000001.

(2) Barsoum, M. W. The $\mathrm{M}_{\mathrm{N}+1} \mathrm{AX}_{\mathrm{N}}$ Phases: A New Class of Solids; Thermodynamically Stable Nanolaminates. Prog. Solid State Chem. 2000, 28 (1-4), 201-281. https://doi.org/10.1016/S0079-6786(00)00006-6.

(3) Barsoum, M. W.; Radovic, M. Elastic and Mechanical Properties of the MAX Phases. Annu. Rev. Mater. Res. 2011, 41 (1), 195-227. https://doi.org/10.1146/annurev-matsci062910-100448.

(4) Barsoum, M. W.; Eklund, P. The $\mathrm{M}_{n+1} \mathrm{AX}_{n}$ Phases: The Precursors for MXenes. In $2 D$ Metal Carbides and Nitrides (MXenes); Anasori, B., Gogotsi, Y., Eds.; Springer International Publishing: Cham, 2019; pp 15-35. https://doi.org/10.1007/978-3-03019026-2_2.

(5) Naguib, M.; Kurtoglu, M.; Presser, V.; Lu, J.; Niu, J.; Heon, M.; Hultman, L.; Gogotsi, Y.; Barsoum, M. W. Two-Dimensional Nanocrystals Produced by Exfoliation of $\mathrm{Ti}_{3} \mathrm{AlC}_{2}$. Adv. Mater. 2011, 23 (37), 4248-4253. https://doi.org/10.1002/adma.201102306.

(6) Radovic, M.; Barsoum, M. W. MAX Phases: Bridging the Gap between Metals and Ceramics. Am. Ceram. Soc. Bull. 2013, 92 (3), 20-27.

(7) Anasori, B.; Lukatskaya, M. R.; Gogotsi, Y. 2D Metal Carbides and Nitrides (MXenes) for Energy Storage. Nat. Rev. Mater. 2017, 2, 16098. https://doi.org/10.1038/natrevmats.2016.98.

(8) Li, N.; Li, Y.; Zhu, X.; Huang, C.; Kai, J.-J.; Fan, J. Theoretical Investigation of the Structure-Property Correlation of MXenes as Anode Materials for Alkali Metal Ion Batteries. J. Phys. Chem. C 2020, 124 (28), 14978-14986. https://doi.org/10.1021/acs.jpcc.0c02968.

(9) Gao, G.; O’Mullane, A. P.; Du, A. 2D MXenes: A New Family of Promising Catalysts for the Hydrogen Evolution Reaction. ACS Catal. 2017, 7 (1), 494-500. https://doi.org/10.1021/acscatal.6b02754.

(10) Su, T.; Peng, R.; Hood, Z. D.; Naguib, M.; Ivanov, I. N.; Keum, J. K.; Qin, Z.; Guo, $\mathrm{Z}$; $\mathrm{Wu}, \mathrm{Z}$. One-Step Synthesis of $\mathrm{Nb}_{2} \mathrm{O}_{5} / \mathrm{C} / \mathrm{Nb}_{2} \mathrm{C}$ (MXene) Composites and Their Use as Photocatalysts for Hydrogen Evolution. ChemSusChem 2018, 11 (4), 688-699. https://doi.org/10.1002/cssc.201702317. 
(11) Ma, T. Y.; Cao, J. L.; Jaroniec, M.; Qiao, S. Z. Interacting Carbon Nitride and Titanium Carbide Nanosheets for High-Performance Oxygen Evolution. Angew. Chem. Int. Ed. 2016, 55 (3), 1138-1142. https://doi.org/10.1002/anie.201509758.

(12) Xie, X.; Chen, S.; Ding, W.; Nie, Y.; Wei, Z. An Extraordinarily Stable Catalyst: Pt NPs Supported on Two-Dimensional $\mathrm{Ti}_{3} \mathrm{C}_{2} \mathrm{X}_{2}(\mathrm{X}=\mathrm{OH}, \mathrm{F})$ Nanosheets for Oxygen Reduction Reaction. Chem. Commun. 2013, 49 (86), 10112. https://doi.org/10.1039/c3cc44428g.

(13) Lin, H.; Gao, S.; Dai, C.; Chen, Y.; Shi, J. A Two-Dimensional Biodegradable Niobium Carbide (MXene) for Photothermal Tumor Eradication in NIR-I and NIR-II Biowindows. J. Am. Chem. Soc. 2017, 139 (45), 16235-16247. https://doi.org/10.1021/jacs.7b07818.

(14) Shahzad, F.; Alhabeb, M.; Hatter, C. B.; Anasori, B.; Man Hong, S.; Koo, C. M.; Gogotsi, Y. Electromagnetic Interference Shielding with 2D Transition Metal Carbides (MXenes). Science 2016, 353 (6304), 1137-1140. https://doi.org/10.1126/science.aag2421.

(15) Song, S.; Liu, J.; Zhou, C.; Jia, Q.; Luo, H.; Deng, L.; Wang, X. $\mathrm{Nb}_{2} \mathrm{O}_{5} / \mathrm{Nb}_{2} \mathrm{CT}_{x}$ Composites with Different Morphologies through Oxidation of $\mathrm{Nb}_{2} \mathrm{CT}_{x}$ MXene for High-Performance Microwave Absorption. J. Alloys Compd. 2020, 843, 155713. https://doi.org/10.1016/j.jallcom.2020.155713.

(16) Sarycheva, A.; Polemi, A.; Liu, Y.; Dandekar, K.; Anasori, B.; Gogotsi, Y. 2D Titanium Carbide (MXene) for Wireless Communication. Sci. Adv. 2018, 4 (9), eaau0920. https://doi.org/10.1126/sciadv.aau0920.

(17) Xie, Y.; Naguib, M.; Mochalin, V. N.; Barsoum, M. W.; Gogotsi, Y.; Yu, X.; Nam, K.W.; Yang, X.-Q.; Kolesnikov, A. I.; Kent, P. R. C. Role of Surface Structure on Li-Ion Energy Storage Capacity of Two-Dimensional Transition-Metal Carbides. J. Am. Chem. Soc. 2014, 136 (17), 6385-6394. https://doi.org/10.1021/ja501520b.

(18) Eames, C.; Islam, M. S. Ion Intercalation into Two-Dimensional Transition-Metal Carbides: Global Screening for New High Capacity Battery Materials. J. Am. Chem. Soc. 2014. https://doi.org/10.1021/ja508154e.

(19) Hart, J. L.; Hantanasirisakul, K.; Lang, A. C.; Anasori, B.; Pinto, D.; Pivak, Y.; van Omme, J. T.; May, S. J.; Gogotsi, Y.; Taheri, M. L. Control of MXenes' Electronic Properties through Termination and Intercalation. Nat. Commun. 2019, 10 (1), 522. https://doi.org/10.1038/s41467-018-08169-8.

(20) Kim, H.; Alshareef, H. N. MXetronics: MXene-Enabled Electronic and Photonic Devices. ACS Mater. Lett. 2020, 2 (1), 55-70. https://doi.org/10.1021/acsmaterialslett.9b00419.

(21) Jeitschko, W.; Nowotny, H.; Benesovsky, F. Kohlenstoffhaltige ternäre Verbindungen (H-Phase). Monatsh Chem 1963, 94, 672-676.

(22) Jeitschko, W.; Nowotny, H.; Benesovsky, F. Die H-Phasen $\mathrm{Ti}_{2} \mathrm{TlC}, \mathrm{Ti}_{2} \mathrm{PbC}, \mathrm{Nb}_{2} \mathrm{InC}$, $\mathrm{Nb}_{2} \mathrm{SnC}$ und $\mathrm{Ta}_{2} \mathrm{GaC}$. Monatsh Chem 1964, 95, 431-435.

(23) Hu, C.; Li, F.; Zhang, J.; Wang, J.; Wang, J.; Zhou, Y. Nb${ }_{4} \mathrm{AlC}_{3}$ : A New Compound Belonging to the MAX Phases. Scr. Mater. 2007, 57 (10), 893-896. https://doi.org/10.1016/j.scriptamat.2007.07.038.

(24) Naguib, M.; Halim, J.; Lu, J.; Cook, K. M.; Hultman, L.; Gogotsi, Y.; Barsoum, M. W. New Two-Dimensional Niobium and Vanadium Carbides as Promising Materials for Li-Ion Batteries. J. Am. Chem. Soc. 2013, 135 (43), 15966-15969. https://doi.org/10.1021/ja405735d.

(25) Ghidiu, M.; Naguib, M.; Shi, C.; Mashtalir, O.; Pan, L. M.; Zhang, B.; Yang, J.; Gogotsi, Y.; Billinge, S. J. L.; Barsoum, M. W. Synthesis and Characterization of 
Two-Dimensional $\mathrm{Nb}_{4} \mathrm{C}_{3}$ (MXene). Chem Commun 2014, 50 (67), 9517-9520. https://doi.org/10.1039/C4CC03366C.

(26) Bai, Y.; He, X.; Wang, R. Lattice Dynamics of Al-Containing MAX-Phase Carbides: A First-Principle Study. J. Raman Spectrosc. 2015, 46 (9), 784-794.

https://doi.org/10.1002/jrs.4720.

(27) Zhang, C.; Beidaghi, M.; Naguib, M.; Lukatskaya, M. R.; Zhao, M.-Q.; Dyatkin, B.; Cook, K. M.; Kim, S. J.; Eng, B.; Xiao, X.; Long, D.; Qiao, W.; Dunn, B.; Gogotsi, Y. Synthesis and Charge Storage Properties of Hierarchical Niobium Pentoxide/Carbon/Niobium Carbide (MXene) Hybrid Materials. Chem. Mater. 2016, 28 (11), 3937-3943. https://doi.org/10.1021/acs.chemmater.6b01244.

(28) Zhao, S.; Meng, X.; Zhu, K.; Du, F.; Chen, G.; Wei, Y.; Gogotsi, Y.; Gao, Y. Li-Ion Uptake and Increase in Interlayer Spacing of $\mathrm{Nb}_{4} \mathrm{C}_{3}$ MXene. Energy Storage Mater. 2017, 8, 42-48. https://doi.org/10.1016/j.ensm.2017.03.012.

(29) Zhang, C. (John); Kim, S. J.; Ghidiu, M.; Zhao, M.-Q.; Barsoum, M. W.; Nicolosi, V.; Gogotsi, Y. Layered Orthorhombic $\mathrm{Nb}_{2} \mathrm{O}_{5} @ \mathrm{Nb}_{4} \mathrm{C}_{3} \mathrm{~T}_{x}$ and $\mathrm{TiO}_{2} @ \mathrm{Ti}_{3} \mathrm{C}_{2} \mathrm{~T}_{x}$ Hierarchical Composites for High Performance Li-Ion Batteries. Adv. Funct. Mater. 2016, 26 (23), 4143-4151. https://doi.org/10.1002/adfm.201600682.

(30) Lipatov, A.; Alhabeb, M.; Lu, H.; Zhao, S.; Loes, M. J.; Vorobeva, N. S.; Dall'Agnese, Y.; Gao, Y.; Gruverman, A.; Gogotsi, Y.; Sinitskii, A. Electrical and Elastic Properties of Individual Single-Layer $\mathrm{Nb}_{4} \mathrm{C}_{3} \mathrm{~T}_{x}$ MXene Flakes. Adv. Electron. Mater. 2020, 6 (4), 1901382. https://doi.org/10.1002/aelm.201901382.

(31) Bortolozo, A. D.; Sant'Anna, O. H.; da Luz, M. S.; dos Santos, C. A. M.; Pereira, A. S.; Trentin, K. S.; Machado, A. J. S. Superconductivity in the $\mathrm{Nb}_{2} \mathrm{SnC}$ Compound. Solid State Commun. 2006, 139 (2), 57-59. https://doi.org/10.1016/j.ssc.2006.05.006.

(32) Scabarozi, T. H.; Roche, J.; Rosenfeld, A.; Lim, S. H.; Salamanca-Riba, L.; Yong, G.; Takeuchi, I.; Barsoum, M. W.; Hettinger, J. D.; Lofland, S. E. Synthesis and Characterization of $\mathrm{Nb}_{2} \mathrm{AlC}$ Thin Films. Thin Solid Films 2009, 517 (9), 2920-2923. https://doi.org/10.1016/j.tsf.2008.12.047.

(33) Kamysbayev, V.; Filatov, A. S.; Hu, H.; Rui, X.; Lagunas, F.; Wang, D.; Klie, R. F.; Talapin, D. V. Covalent Surface Modifications and Superconductivity of TwoDimensional Metal Carbide MXenes. Science 2020, eaba8311. https://doi.org/10.1126/science.aba8311.

(34) Lue, C. S.; Lin, J. Y.; Xie, B. X. NMR Study of the Ternary Carbides $\mathrm{M}_{2} \mathrm{AlC}$ (M=Ti,V,Cr). Phys. Rev. B 2006, 73 (3), 035125. https://doi.org/10.1103/PhysRevB.73.035125.

(35) Harris, K. J.; Bugnet, M.; Naguib, M.; Barsoum, M. W.; Goward, G. R. Direct Measurement of Surface Termination Groups and Their Connectivity in the 2D MXene $\mathrm{V}_{2} \mathrm{CT}_{x}$ Using NMR Spectroscopy. J. Phys. Chem. C 2015, 13713-13720. https://doi.org/10.1021/acs.jpcc.5b03038.

(36) Hope, M. A.; Forse, A. C.; Griffith, K. J.; Lukatskaya, M. R.; Ghidiu, M.; Gogotsi, Y.; Grey, C. P. NMR Reveals the Surface Functionalisation of $\mathrm{Ti}_{3} \mathrm{C}_{2}$ MXene. Phys. Chem. Chem. Phys. 2016, 18 (7). https://doi.org/10.1039/c6cp00330c.

(37) Anayee, M.; Kurra, N.; Alhabeb, M.; Seredych, M.; Hedhili, M. N.; Emwas, A.-H.; Alshareef, H. N.; Anasori, B.; Gogotsi, Y. Role of Acid Mixtures Etching on the Surface Chemistry and Sodium Ion Storage in $\mathrm{Ti}_{3} \mathrm{C}_{2} \mathrm{~T}_{x}$ MXene. Chem. Commun. 2020, 56 (45), 6090-6093. https://doi.org/10.1039/D0CC01042A.

(38) Kobayashi, T.; Sun, Y.; Prenger, K. E.; Jiang, D.-E.; Naguib, M.; Pruski, M. On the Nature of Terminating Hydroxyl Groups and Intercalating Water in $\mathrm{Ti}_{3} \mathrm{C}_{2} \mathrm{~T}_{x}$ MXenes: A Study by ${ }^{1} \mathrm{H}$ Solid-State NMR and DFT Calculations. J. Phys. Chem. C 2020. https://doi.org/10.1021/acs.jpcc.0c04744. 
(39) Chien, P.-H.; Griffith, K. J.; Liu, H.; Gan, Z.; Hu, Y.-Y. Recent Advances in SolidState Nuclear Magnetic Resonance Techniques for Materials Research. Annu. Rev. Mater. Res. 2020, 50 (1), 493-520. https://doi.org/10.1146/annurev-matsci-091019011049.

(40) Hung, I.; Zhou, L.; Pourpoint, F.; Grey, C. P.; Gan, Z. Isotropic High Field NMR Spectra of Li-Ion Battery Materials with Anisotropy $>1$ MHz. J. Am. Chem. Soc. 2012, 134 (4), 1898-1901. https://doi.org/10.1021/ja209600m.

(41) Pecher, O.; Halat, D. M.; Lee, J.; Liu, Z.; Griffith, K. J.; Braun, M.; Grey, C. P. Enhanced Efficiency of Solid-State NMR Investigations of Energy Materials Using an External Automatic Tuning/Matching (eATM) Robot. J. Magn. Reson. 2017, 275, 127-136. https://doi.org/10.1016/j.jmr.2016.12.008.

(42) Lipton, A. S.; Wright, T. A.; Bowman, M. K.; Reger, D. L.; Ellis, P. D. Solid-State ${ }^{67} \mathrm{Zn}$ NMR Spectroscopy in Bioinorganic Chemistry. Spectra of Four- and SixCoordinate Zinc Pyrazolylborate Complexes Obtained by Management of Proton Relaxation Rates with a Paramagnetic Dopant. J. Am. Chem. Soc. 2002, 124 (20), 5850-5860. https://doi.org/10.1021/ja0127133.

(43) Prasad, S.; Zhao, P.; Huang, J.; Fitzgerald, J. J.; Shore, J. S. Niobium-93 MQMAS NMR Spectroscopic Study of Alkali and Lead Niobates. Solid State Nucl. Magn. Reson. 2001, 19 (1), 45-62. https://doi.org/10.1006/snmr.2000.0022.

(44) Stone, N. J. Table of Nuclear Electric Quadrupole Moments. At. Data Nucl. Data Tables 2016, 111 (Supplement C), 1-28. https://doi.org/10.1016/j.adt.2015.12.002.

(45) Jakobsen, H. J.; Skibsted, J.; Bildsøe, H.; Nielsen, N. Chr. Magic-Angle Spinning NMR Spectra of Satellite Transitions for Quadrupolar Nuclei in Solids. J. Magn. Reson. 1989, 85, 173-180.

(46) Mackenzie, K. J. D.; Smith, M. E. Multinuclear Solid-State NMR of Inorganic Materials; Pergamon Materials Series; Pergamon: London, 2002; Vol. 6.

(47) Myhra, S.; Crossley, J. A. A.; Barsoum, M. W. Crystal-Chemistry of the $\mathrm{Ti}_{3} \mathrm{AlC}_{2}$ and $\mathrm{Ti}_{4} \mathrm{AlN}_{3}$ Layered Carbide/Nitride Phases-Characterization by XPS. J. Phys. Chem. Solids 2001, 62 (4), 811-817. https://doi.org/10.1016/S0022-3697(00)00268-7.

(48) Bräuniger, T.; Jansen, M. Solid-State NMR Spectroscopy of Quadrupolar Nuclei in Inorganic Chemistry. Z. Für Anorg. Allg. Chem. 2013, 639 (6), 857-879. https://doi.org/10.1002/zaac.201300102.

(49) Bräuniger, T.; Chandran, C. V.; Wedig, U.; Jansen, M. NMR Chemical Shift and Quadrupolar Interaction Parameters of Carbon-Coordinated ${ }^{27} \mathrm{Al}$ in Aluminium Carbide, $\mathrm{Al}_{4} \mathrm{C}_{3}$. Z. Für Anorg. Allg. Chem. 2011, 637 (5), 530-535. https://doi.org/10.1002/zaac.201000445.

(50) Marti, R. M.; Sarou-Kanian, V.; Moran, C. M.; Walton, K. S.; Hayes, S. E. NMR Crystallography of Aluminum Carbide: Impurities in the Reagent and Improved ${ }^{27} \mathrm{Al}$ NMR Tensors. J. Phys. Chem. C 2020, 124 (13), 7238-7243. https://doi.org/10.1021/acs.jpcc.9b11579.

(51) Butler, N. D.; Dupree, R.; Lewis, M. H. The Use of Magic-Angle-Spinning NMR in Structural Studies of Si-Al-O-N Phases. J. Mater. Sci. Lett. 1984, 3 (5), 469-470. https://doi.org/10.1007/BF00724394.

(52) Dupree, R.; Lewis, M. H.; Smith, M. E. Structural Characterization of Ceramic Phases with High-Resolution ${ }^{27}$ Al NMR. J. Appl. Crystallogr. 1988, 21, 109-116.

(53) Bräuniger, T.; Kempgens, P.; Harris, R. K.; Howes, A. P.; Liddell, K.; Thompson, D. P. A Combined ${ }^{14} \mathrm{~N} /{ }^{27} \mathrm{Al}$ Nuclear Magnetic Resonance and Powder X-Ray Diffraction Study of Impurity Phases in $\beta$-Sialon Ceramics. Solid State Nucl. Magn. Reson. 2003, 23 (1-2), 62-76. https://doi.org/10.1016/S0926-2040(02)00016-4. 
(54) Cozzan, C.; Griffith, K. J.; Laurita, G.; Hu, J. G.; Grey, C. P.; Seshadri, R. Structural Evolution and Atom Clustering in $\beta$-SiAlON: $\beta$ - $\mathrm{Si}_{6-z} \mathrm{Al}_{z} \mathrm{O}_{z} \mathrm{~N}_{8-z}$. Inorg. Chem. 2017, 56 (4), 2153-2158. https://doi.org/10.1021/acs.inorgchem.6b02780.

(55) Kim, H. S.; Bugli, G.; Djéga-Mariadassou, G. Preparation and Characterization of Niobium Carbide and Carbonitride. J. Solid State Chem. 1999, 142 (1), 100-107. https://doi.org/10.1006/jssc.1998.7993.

(56) Rempel, A. A.; Gusev, A. I.; Belyaev, M. Y. ${ }^{93} \mathrm{Nb}$ NMR Study of an Ordered and a Disordered Non-Stoichiometric Niobium Carbide. J. Phys. C Solid State Phys. 1987, 20 (34), 5655-5666. https://doi.org/10.1088/0022-3719/20/34/005.

(57) Froidevaux, C.; Rossier, D. N.M.R. Investigation of the Atomic and Electronic Structure of Vanadium and Niobium Carbides. J. Phys. Chem. Solids 1967, 28 (7), 1197-1209. https://doi.org/10.1016/0022-3697(67)90063-7.

(58) Sarycheva, A.; Gogotsi, Y. Raman Spectroscopy Analysis of the Structure and Surface Chemistry of $\mathrm{Ti}_{3} \mathrm{C}_{2} \mathrm{~T}_{x}$ MXene. Chem. Mater. 2020, 32 (8), 3480-3488. https://doi.org/10.1021/acs.chemmater.0c00359.

(59) Mashtalir, O.; Lukatskaya, M. R.; Zhao, M.-Q.; Barsoum, M. W.; Gogotsi, Y. AmineAssisted Delamination of $\mathrm{Nb}_{2} \mathrm{C}$ MXene for Li-Ion Energy Storage Devices. Adv. Mater. 2015, 27 (23), 3501-3506. https://doi.org/10.1002/adma.201500604.

(60) Cockreham, C. B.; Zhang, X.; Li, H.; Hammond-Pereira, E.; Sun, J.; Saunders, S. R.; Wang, Y.; Xu, H.; Wu, D. Inhibition of $\mathrm{AlF}_{3} \cdot 3 \mathrm{H}_{2} \mathrm{O}$ Impurity Formation in $\mathrm{Ti}_{3} \mathrm{C}_{2} \mathrm{~T}_{x}$ MXene Synthesis under a Unique $\mathrm{CoFx} / \mathrm{HCl}$ Etching Environment. ACS Appl. Energy Mater. 2019, 2 (11), 8145-8152. https://doi.org/10.1021/acsaem.9b01618.

(61) Seredych, M.; Shuck, C. E.; Pinto, D.; Alhabeb, M.; Precetti, E.; Deysher, G.; Anasori, B.; Kurra, N.; Gogotsi, Y. High-Temperature Behavior and Surface Chemistry of Carbide MXenes Studied by Thermal Analysis. Chem. Mater. 2019, 31 (9), 3324 3332. https://doi.org/10.1021/acs.chemmater.9b00397.

(62) Grey, C. P.; Vega, A. J. Determination of the Quadrupole Coupling Constant of the Invisible Aluminum Spins in Zeolite HY with ${ }^{1} \mathrm{H} /{ }^{27} \mathrm{Al}$ TRAPDOR NMR. J. Am. Chem. Soc. 1995, 117 (31), 8232-8242. https://doi.org/10.1021/ja00136a022.

(63) Persson, I.; Halim, J.; Hansen, T. W.; Wagner, J. B.; Darakchieva, V.; Palisaitis, J.; Rosen, J.; Persson, P. O. Å. How Much Oxygen Can a MXene Surface Take Before It Breaks? Adv. Funct. Mater. 2020, 1909005. https://doi.org/10.1002/adfm.201909005.

(64) König, R.; Scholz, G.; Pawlik, a.; Jager, C.; Van Rossum, B.; Kemnitz, E. Identification of $\mathrm{AlF}_{x}(\mathrm{OR})_{y}$ Species in Strongly Disordered Aluminum Isopropoxide Fluoride Solids: A Field-Dependent MAS NMR Study. J. Phys. Chem. C 2009, 113, 15576-15585. https://doi.org/10.1021/jp9066795.

(65) Mouras, S.; Hamwi, A.; Djurado, D.; Cousseins, J. C.; Fawal, Z.; Hajji Mohamad, A.; Dupuis, J. ${ }^{19}$ F NMR Study of Niobium Pentafluoride-Graphite Intercalation Compounds Prepared under Fluorine Atmosphere. J. Solid State Chem. 1989, 83, 115120. https://doi.org/10.1016/0022-4596(89)90060-1

(66) Bloch, F.; Siegert, A. Magnetic Resonance for Nonrotating Fields. Phys. Rev. 1940, 57 (6), 522-527. https://doi.org/10.1103/PhysRev.57.522.

(67) Emsley, L.; Bodenhausen, G. Phase Shifts Induced by Transient Bloch-Siegert Effects in NMR. Chem. Phys. Lett. 1990, 168 (3-4), 297-303. https://doi.org/10.1016/00092614(90)85614-I.

(68) Sugahara, A.; Ando, Y.; Kajiyama, S.; Yazawa, K.; Gotoh, K.; Otani, M.; Okubo, M.; Yamada, A. Negative Dielectric Constant of Water Confined in Nanosheets. Nat. Commun. 2019, 10 (1), 850. https://doi.org/10.1038/s41467-019-08789-8. 
(69) Tzenov, N. V.; Barsoum, M. W. Synthesis and Characterization of Ti $\mathrm{AlC}_{2} . J . \mathrm{Am}$. Ceram. Soc. 2004, 83 (4), 825-832. https://doi.org/10.1111/j.11512916.2000.tb01281.x.

(70) Lucier, B. E. G.; Huang, Y. Chapter One - Reviewing ${ }^{47 / 49}$ Ti Solid-State NMR Spectroscopy: From Alloys and Simple Compounds to Catalysts and Porous Materials. In Annual Reports on NMR Spectroscopy; Webb, G. A., Ed.; Academic Press, 2016; Vol. 88, pp 1-78.

(71) Xu, J.; Lucier, B. E. G.; Lin, Z.; Sutrisno, A.; Terskikh, V. V.; Huang, Y. New Insights into the Short-Range Structures of Microporous Titanosilicates As Revealed by ${ }^{47 / 49} \mathrm{Ti}$, ${ }^{23} \mathrm{Na},{ }^{39} \mathrm{~K}$, and ${ }^{29} \mathrm{Si}$ Solid-State NMR Spectroscopy. J. Phys. Chem. C 2014, 118 (47), 27353-27365. https://doi.org/10.1021/jp5077966. 